\title{
A turquoise fluorescence lifetime-based biosensor for quantitative imaging of intracellular calcium
}

Franka H. van der Linden ${ }^{1}$, Eike K. Mahlandt ${ }^{1}$, Janine J.G. Arts ${ }^{1,2}$, Joep Beumer ${ }^{3}$, Jens Puschhof ${ }^{3}$, Saskia M.A. de Man ${ }^{1}$, Anna O. Chertkova ${ }^{1}$, Bas Ponsioen ${ }^{4}$, Hans Clevers 3 , Jaap D. van Buul ${ }^{1,2}$, Marten Postma ${ }^{1}$, Theodorus W.J. Gadella Jr. ${ }^{1}$ \& Joachim Goedhart ${ }^{1, *}$

\section{Affiliations:}

${ }^{1}$ Swammerdam Institute for Life Sciences, Section of Molecular Cytology, van Leeuwenhoek Centre for Advanced Microscopy, University of Amsterdam, Amsterdam, the Netherlands.

2 Department of Molecular Hematology at Sanquin Research and Landsteiner Laboratory, Academic Medical Centre, University of Amsterdam, the Netherlands

${ }^{3}$ Oncode Institute, Hubrecht Institute, Royal Netherlands Academy of Arts and Sciences and University Medical Center, Utrecht, the Netherlands.

${ }^{4}$ Oncode Institute, Center for Molecular Medicine, University Medical Centre Utrecht, Utrecht, the Netherlands.

*Correspondence:

Email: j.goedhart@uva.nl | Twitter: @joachimgoedhart | ORCID: 0000-0002-0630-3825 

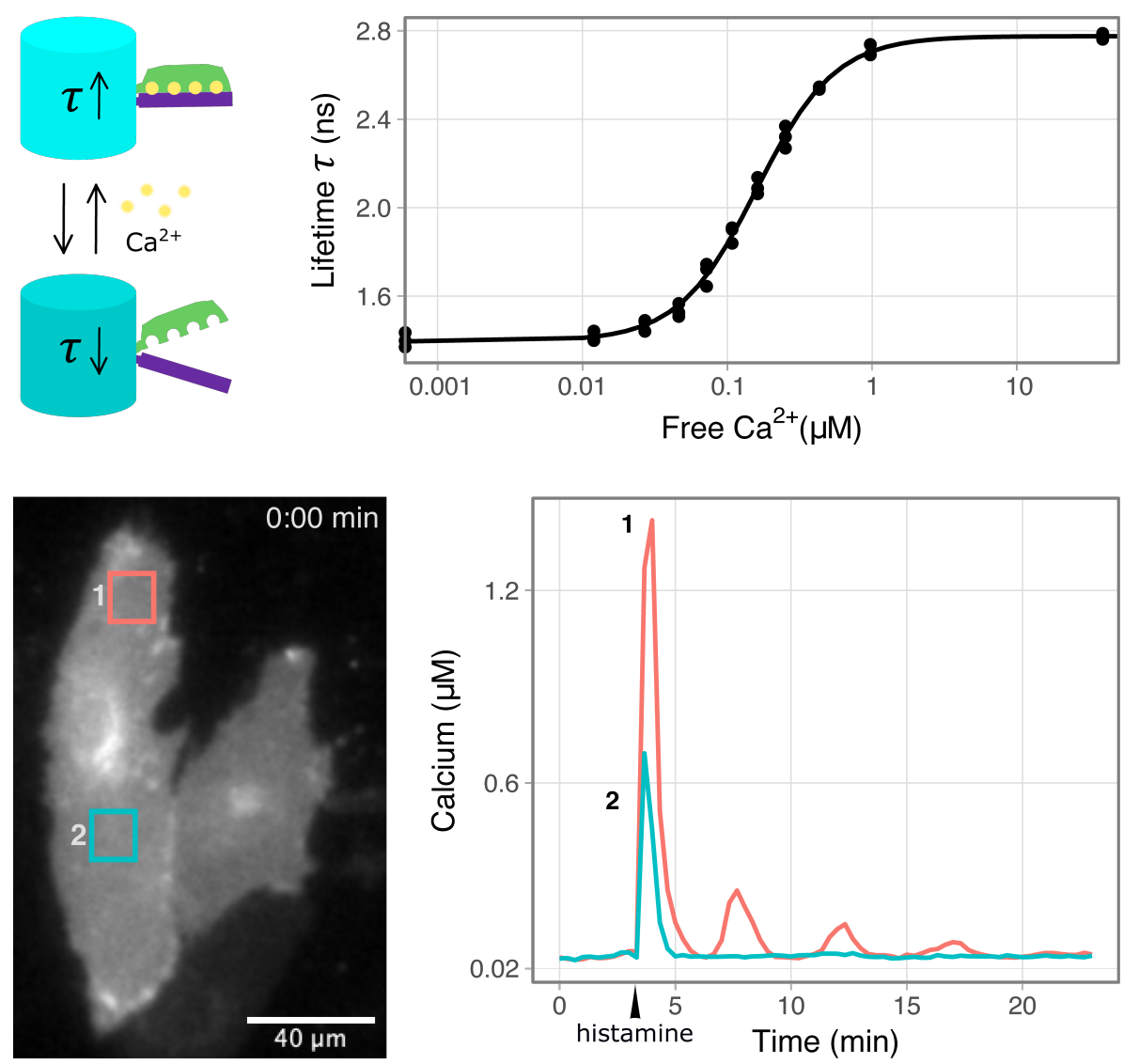

\section{Abstract}

The most successful genetically encoded calcium indicators (GECIs) employ an intensity or intensiometric readout. Despite a large calcium-dependent change in fluorescence intensity, the quantification of calcium concentrations with GECIs is problematic, which is further complicated by the sensitivity of all GECIs to changes in the $\mathrm{pH}$ in the biological range. Here, we report on a novel sensing strategy in which a conformational change directly modifies the fluorescence quantum yield and fluorescence lifetime of a circular permutated turquoise fluorescent protein. The fluorescence lifetime is an absolute parameter that enables straightforward quantification, eliminating intensity-related artifacts. A new engineering strategy that optimizes lifetime contrast led to a biosensor that shows a 3-fold change in the calcium-dependent quantum yield and a fluorescence lifetime change of $1.3 \mathrm{~ns}$. Additionally, the response of the calcium sensor is insensitive to $\mathrm{pH}$ between 6.2-9. As a result, the turquoise GECI enables robust measurements of intracellular calcium concentrations by fluorescence lifetime imaging. We demonstrate quantitative imaging of calcium concentration with the turquoise GECI in single endothelial cells and human-derived organoids. 


\section{Main text}

Genetically encoded calcium indicators (GECIs) are popular tools for probing intracellular calcium levels ${ }^{1}$. Fierce engineering efforts have led to calcium probes with an impressive intensity contrast, enabling functional imaging in complex tissue and animals ${ }^{2,3}$. The probe design that delivers the largest intensity contrast uses a circular permutated green fluorescent protein (cpGFP) flanked by calmodulin (CaM) and a peptide that binds calcium-bound calmodulin ${ }^{3-5}$. The calcium-dependent interaction between calmodulin and the peptide results in a conformation change that is converted into a change in fluorescence intensity of the cpGFP. These probes are also known as GCaMP or GECO6. Alternatively, chemical dyes have been used for calcium sensing, but they are limited in application to cellular cultures and they are, unlike GECIs, not targetable to specific organelles ${ }^{7}$.

Despite their success, the GCaMP-type probes have limitations. First, the intensity-based read-out hinders quantification. The calcium levels modify the fluorescent intensity of the cpGFP. However, fluorescence intensity can also be changed by many additional factors, including photobleaching, sample movement, and changes in (local) probe concentration $^{8}$, making it inherently difficult to quantify. Second, GCaMP type probes are sensitive to $\mathrm{pH}^{9,10}$. The binding of calcium changes the $\mathrm{p} K_{a}$ of the cpGFP, which results in a change in the protonation of the chromophore, which ultimately leads to the intensity change $^{11}$. The $\mathrm{p} K_{a}$ of GECIs is near the physiological $\mathrm{pH}$ and therefore a change in intracellular $\mathrm{pH}$ also changes the intensity. Together, these factors complicate true quantitative imaging of calcium.

Efforts have been made to correct for some these effects by ratio imaging using a second fluorescent protein (FP), usually an orange or red variant ${ }^{12,13}$. Unfortunately, the ratio depends on the intensity of the second FP, which is turn is determined by its maturation ${ }^{12}$ (Figure S1). In addition, these sensors have inherited the $\mathrm{pH}$ sensitivity of their parents ${ }^{12,13}$. FRET-based probes are another alternative but have the same issues with unequal maturation rates of the two fluorescent proteins. Also, the widely used yellow FP as acceptor is relatively $\mathrm{pH}$ sensitive ${ }^{14}$.

We observed for both types of ratiometric sensors a high variability in emission ratio between cells (Figure S1, Table S1). This variability hinders quantification and demands establishment of the dynamic range for each individual cell. In addition, intensity and therefore ratio-imaging is dependent on instrumentation and therefore data obtained on different microscopes are not comparable. Lastly, FRET and ratio-imaging requires a large portion of the visible spectrum, reducing possibilities for multiplexing. 
bioRxiv preprint doi: https://doi.org/10.1101/2021 06.21 .449214 ; this version posted June 21,2021 . The copyright holder for this preprint (which was not certified by peer review) is the author/funder, who has granted bioRxiv a license to display the preprint in perpetuity. It is made available under aCC-BY-NC-ND 4.0 International license.

A
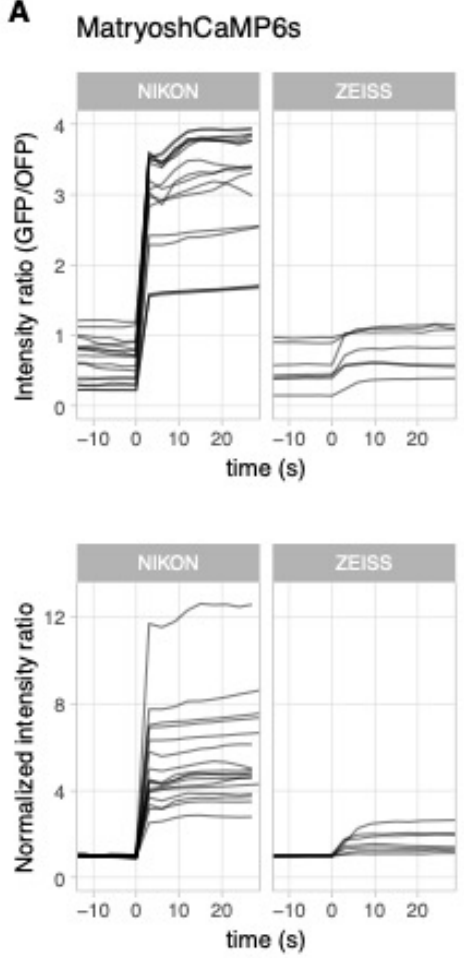

YCaM3.60
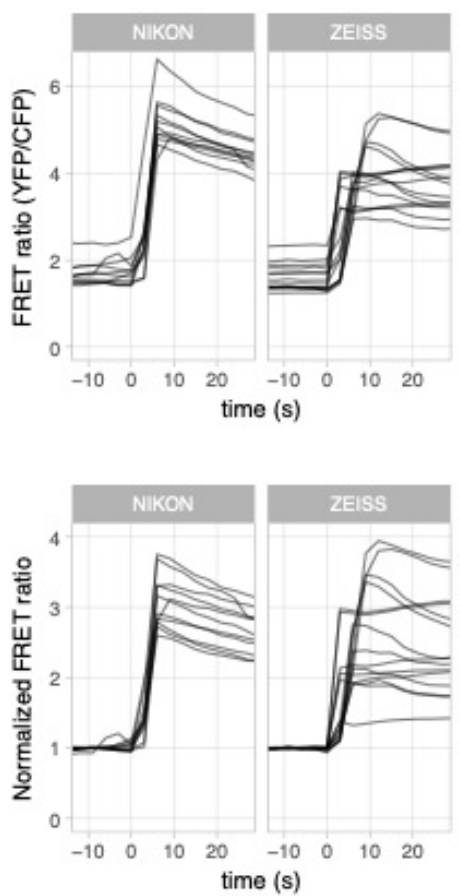

B Influence maturation on
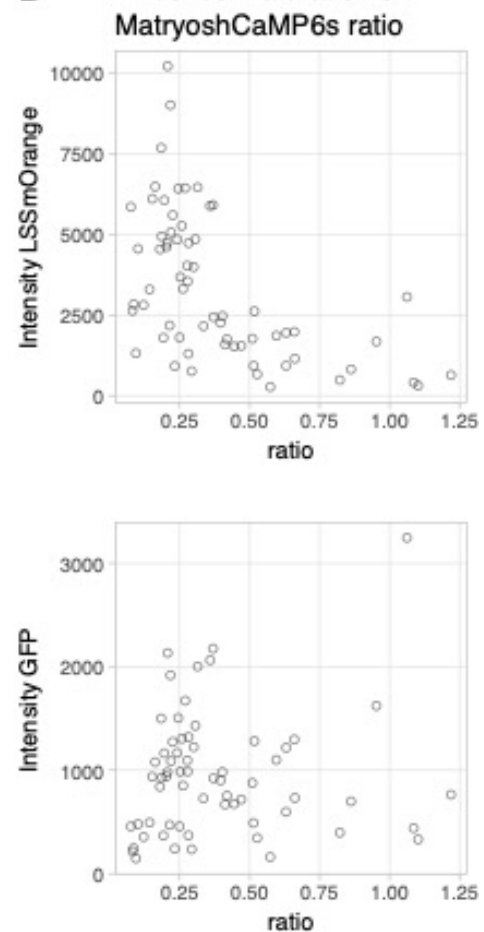

Figure S1. Ratiometric measurements of MatryoshCaMP6s and YCaM3.60 in HeLa cells. A) Timeseries of individual cells stimulated at $\mathrm{t}=0$ with $14 \mathrm{mM}$ ionomycin combined with $5 \mathrm{mM} \mathrm{CaCl}_{2}(n=7$ to 17), taken on two different microscopes, a NIKON and a ZEISS setup. Top panels show the intensity ratio, bottom panels show the ratio normalized to the first three frames. Both ratio and normalized ratio give a highly variable output. B) The intensity of LSSmOrange of MatryoshCaMP6s (top panel) shows a clear influence on the measured ratio, which is not the case for the green fluorescence (bottom panel). Dots indicate individual cells $(\mathrm{n}=64)$.

Table S1. Variation of the output of different calcium sensors in HeLa cells. The respective fluorescent property was measured for each sensor before (pre) and after (post) addition of $14 \mathrm{mM}$ ionomycin combined with $5 \mathrm{mM} \mathrm{CaCl}_{2}$. For lifetime measurements both the phase and modulation lifetimes are indicated. The mean, standard deviation (sd) and coefficient of variation (CV, sd divided by mean) of individual cells are given. $\mathrm{CV}$ is a number for the variation, independent of the absolute value, and can therefore be used to compare the variation of different types of readouts. Tq-Ca-FLITS published here was added for comparison and shows the lowest $\mathrm{CV}$ of all sensors.

\begin{tabular}{lllllll}
\hline Sensor & Measured property & state & N & mean & sd & CV \\
\hline \multirow{2}{*}{ Tq-Ca-FLITS } & phase lifetime (ns) & pre & 110 & 1.45 & 0.036 & 0.025 \\
& & post & 110 & 2.77 & 0.035 & 0.013 \\
& modulation lifetime (ns) & pre & 110 & 1.84 & 0.055 & 0.030 \\
& & post & 110 & 2.94 & 0.034 & 0.012 \\
jRCaMP1b & phase lifetime (ns) & pre & 29 & 1.60 & 0.120 & 0.075 \\
& & post & 56 & 2.78 & 0.040 & 0.014 \\
& modulation lifetime (ns) & pre & 29 & 2.35 & 0.103 & 0.044 \\
& & post & 56 & 3.02 & 0.055 & 0.018 \\
RCaMP1h & phase lifetime (ns) & pre & 31 & 1.05 & 0.049 & 0.047 \\
& & post & 69 & 2.74 & 0.040 & 0.014 \\
& \multirow{2}{*}{ modulation lifetime (ns) } & pre & 31 & 1.72 & 0.079 & 0.046 \\
MatryoshCaMP6s & \multirow{2}{*}{ intensity ratio (GFP/OFP) } & post & 69 & 2.97 & 0.049 & 0.017 \\
& & pre & 7 & 0.54 & 0.291 & 0.536 \\
YCaM3.60 & \multirow{2}{*}{ FRET ratio (YFP/CFP) } & pre & & 0.83 & 0.307 & 0.368 \\
& & post & 15 & 1.58 & 0.305 & 0.192 \\
& & & & & & \\
& & & & & \\
\end{tabular}


bioRxiv preprint doi: https://doi.org/10.1101/2021.06.21.449214; this version posted June 21, 2021. The copyright holder for this preprint (which was not certified by peer review) is the author/funder, who has granted bioRxiv a license to display the preprint in perpetuity. It is made available under aCC-BY-NC-ND 4.0 International license.

The excited state fluorescence lifetime of a fluorescent molecule is generally not influenced by intensity-related factors ${ }^{15-17}$, and has been used successfully for quantitative imaging ${ }^{18-22}$. Consequently, GECI probes based on lifetime contrast would enable true quantitative calcium imaging, independent of equipment. However, most current GECIs, including GCaMPs and FRET-based GECIs, show hardly any or no QY or lifetime contrast (Figure S2, Table S2), despite a clear intensity change ${ }^{23,24}$. For the FRET-sensors this is caused by a close to $100 \%$ efficiency in energy transfer in one of the states of the sensor. In cpGFP based sensors the intensity change is predominantly caused by a change in extinction coefficient $(\varepsilon)$, without a significant change in quantum yield $(Q Y)^{3,23}$ (Table S2). This leads to an absence of lifetime change since the lifetime of fluorescent proteins is proportional to the $Q Y$.

Exceptions are RCaMP1h and jRCaMP1b, which are intensity-based calcium sensors that employ a red fluorescent protein instead of a GFP and they show a $Q Y$ and lifetime contrast ${ }^{25,26}$. However, these probes display $\mathrm{pH}$ sensitivity in the biological range and a lower calcium sensitivity compared to other sensors. In addition, they have a very low intensity in the calcium-free state, complicating lifetime measurements (Figure S3, Table S2).
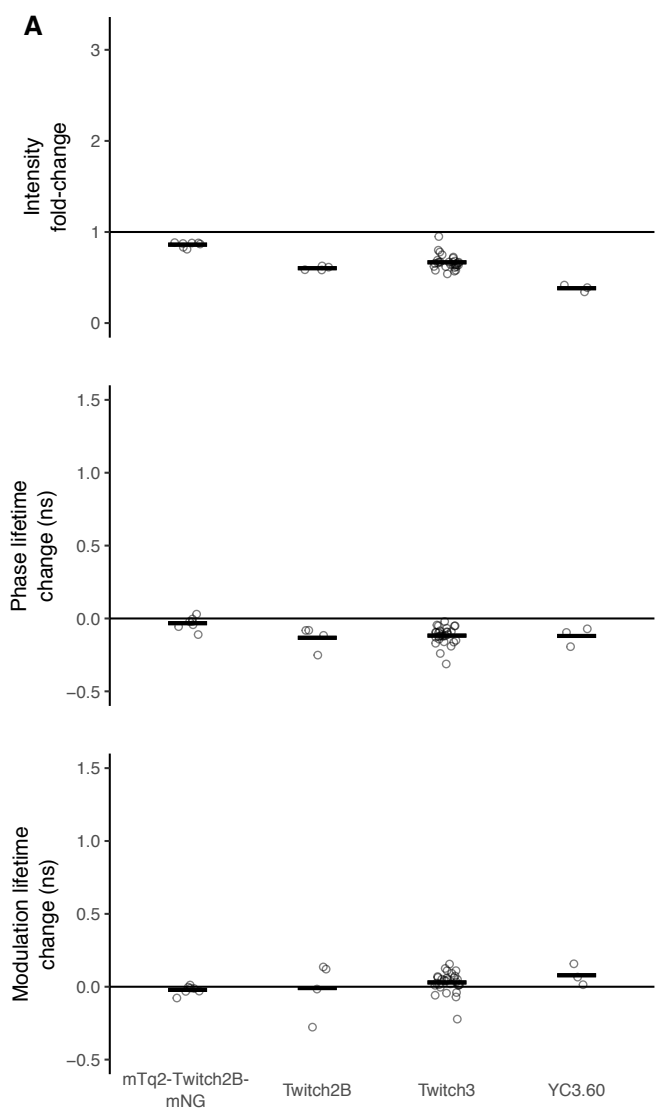
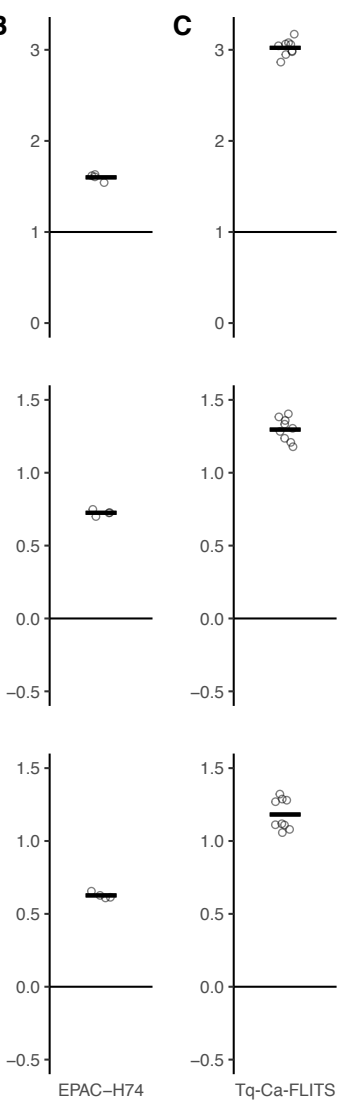

Figure S2. Intensity and lifetime contrast of biosensors. A) YCaM3.60, Twitch3, Twitch2B and mTq2-Twitch2B-mNG were transiently expressed in HeLa cells. Intensity and donor lifetimes were recorded before and after stimulation with $14 \mathrm{mM}$ ionomycin combined with $5 \mathrm{mM} \mathrm{CaCl}_{2}$ ( $n=3$ to 29). The intensity fold-change (top panel) and the absolute modulation and phase lifetime change (middle and bottom panel) of the donor fluorescent protein are plotted. B) Published donor intensity and lifetime change of EPAC-H74, a FRET-FLIM sensor for cyclic AMP27 $(n=4)$ with a substantial lifetime contrast. C) For comparison we show the performance of new Turquoise calcium biosensor (TqCa-FLITS). HeLa cells were transiently transfected with the sensor and stimulated with $14 \mathrm{mM}$ ionomycin and $5 \mathrm{mM} \mathrm{CaCl}_{2}$ while imaging $(n=9)$. Individual cell responses (circles) and their mean (line) are plotted for all sensors. 
bioRxiv preprint doi: https://doi org/101101/2021.06.21449214; this version posted June 21 2021. The copyright holder for this preprint (which was not certified by peer review) is the author/funder, who has granted bioRxiv a license to display the preprint in perpetuity. It is made available under aCC-BY-NC-ND 4.0 International license.

Table S2. Properties of current intensity-based calcium sensors. Properties of the parent FP are also included: EGFP for all green sensors, FusionRed for K-GEC01, mApple for R-GECO1, mRuby for RCaMP1h and jRCaMP1b, mTurquoise 2 for Tq-Ca-FLITS. mScarlet demonstrates the theoretical possibility for improvement of the brightness of the red sensors. Horizontal color bars indicate the relative intrinsic brightness compared to sensors and FPs of the same color (green, red or cyan). Tq-Ca-FLITS published here was added for comparison, which has a notably much higher relative intrinsic brightness in the calcium free state compared to other sensors. EC indicates the extinction coefficient, QY the quantum yield.

References: a - Zhao et al. (2011) ${ }^{6}$, b - Dana et al. (2019) ${ }^{3}$, c - Patterson et al. (2001) ${ }^{28}$, d - Shen et al. $(2018)^{29}$, e - Shemiakina et al. (2012) ${ }^{30}$, f - Bindels et al. (2017) ${ }^{31}$, g - Dana et al. (2016) ${ }^{26}$, h - Kredel et al. (2009) $)^{32}$, i - Goedhart et al. (2012) 33 , j - Cranfill et al. (2016)

\begin{tabular}{|c|c|c|c|c|c|c|c|}
\hline & & $\begin{array}{c}\text { EC } \\
(\mathrm{M}-1 \mathrm{~cm}-1)\end{array}$ & QY & $\begin{array}{c}\text { Kd } \\
(n M)\end{array}$ & p Ka & $\begin{array}{c}\text { Intrinsic } \\
\text { brightness }\end{array}$ & Ref. \\
\hline GCaMP3 & $\begin{array}{l}\text { apo } \\
\text { sat }\end{array}$ & $\begin{array}{l}11000 \\
50000\end{array}$ & $\begin{array}{c}0.2 \\
0.44\end{array}$ & 542 & $\begin{array}{c}8.73 \\
6.6\end{array}$ & $\begin{array}{c}2200 \\
22000\end{array}$ & $\mathrm{a}$ \\
\hline GCaMP6f & $\begin{array}{l}\text { apo } \\
\text { sat }\end{array}$ & $\begin{array}{c}2761 \\
66293\end{array}$ & $\begin{array}{l}0.57 \\
0.66\end{array}$ & 297 & $\begin{array}{l}7.72 \\
6.25\end{array}$ & $\begin{array}{c}1574 \\
43753\end{array}$ & $\mathrm{~b}$ \\
\hline GCaMP6s & $\begin{array}{l}\text { apo } \\
\text { sat }\end{array}$ & $\begin{array}{c}2118 \\
70117\end{array}$ & $\begin{array}{l}0.41 \\
0.64\end{array}$ & 147 & $\begin{array}{l}7.54 \\
6.03\end{array}$ & $\begin{array}{c}868 \\
44875\end{array}$ & $\mathrm{~b}$ \\
\hline jGCaMP7f & $\begin{array}{l}\text { apo } \\
\text { sat }\end{array}$ & $\begin{array}{c}2358 \\
56028\end{array}$ & $\begin{array}{l}0.47 \\
0.59\end{array}$ & 174 & $\begin{array}{c}7.88 \\
6.5\end{array}$ & $\begin{array}{c}1108 \\
33057\end{array}$ & $\mathrm{~b}$ \\
\hline jGCaMP7s & $\begin{array}{l}\text { apo } \\
\text { sat }\end{array}$ & $\begin{array}{c}554 \\
53068\end{array}$ & $\begin{array}{l}0.58 \\
0.65\end{array}$ & 68 & $\begin{array}{l}7.69 \\
6.36\end{array}$ & $\begin{array}{c}321 \\
34494\end{array}$ & $\mathrm{~b}$ \\
\hline jGCaMP7 c & $\begin{array}{l}\text { apo } \\
\text { sat }\end{array}$ & $\begin{array}{c}1541 \\
49566\end{array}$ & $\begin{array}{c}0.5 \\
0.59\end{array}$ & 298 & $\begin{array}{l}8.66 \\
6.66\end{array}$ & $\begin{array}{c}771 \\
29244\end{array}$ & $\mathrm{~b}$ \\
\hline jGCaMP7b & $\begin{array}{l}\text { apo } \\
\text { sat }\end{array}$ & $\begin{array}{c}5668 \\
56462\end{array}$ & $\begin{array}{c}0.59 \\
0.6\end{array}$ & 82 & $\begin{array}{l}7.82 \\
6.37\end{array}$ & $\begin{array}{c}3344 \\
33877\end{array}$ & $\mathrm{~b}$ \\
\hline EGFP & & 55000 & 0.6 & & 5.9 & 33000 & $\mathrm{c}$ \\
\hline K-GECO1 & $\begin{array}{l}\text { apo } \\
\text { sat }\end{array}$ & $\begin{array}{l}19000 \\
61000\end{array}$ & $\begin{array}{l}0.12 \\
0.45\end{array}$ & 165 & $\begin{array}{c}6.71,8.23 \\
6.34\end{array}$ & $\begin{array}{c}2280 \\
27450\end{array}$ & d \\
\hline FusionRed & & 94500 & 0.19 & & 4.6 & 17955 & e \\
\hline R-GECO1 & $\begin{array}{l}\text { apo } \\
\text { sat }\end{array}$ & $\begin{array}{l}15000 \\
51000\end{array}$ & $\begin{array}{c}0.06 \\
0.2\end{array}$ & 482 & $\begin{array}{c}8.9 \\
6.59\end{array}$ & $\begin{array}{c}900 \\
10200\end{array}$ & $\mathrm{a}$ \\
\hline mApple & & 82000 & 0.47 & & 6.5 & 38540 & $\mathrm{f}$ \\
\hline RCaMP1h & $\begin{array}{l}\text { apo } \\
\text { sat }\end{array}$ & $\begin{array}{l}20800 \\
63600\end{array}$ & $\begin{array}{c}0.13 \\
0.6\end{array}$ & 1127 & $\begin{array}{l}7.1 \\
5.7\end{array}$ & $\begin{array}{c}2704 \\
38160\end{array}$ & g \\
\hline jRCaMP1b & $\begin{array}{l}\text { apo } \\
\text { sat }\end{array}$ & $\begin{array}{l}25300 \\
53400\end{array}$ & $\begin{array}{l}0.15 \\
0.54\end{array}$ & 712 & $\begin{array}{l}6.4 \\
5.5\end{array}$ & $\begin{array}{c}3795 \\
28836\end{array}$ & g \\
\hline $\begin{array}{l}\text { mRuby } \\
\text { mScarlet }\end{array}$ & & $\begin{array}{l}112000 \\
100000 \\
\end{array}$ & $\begin{array}{c}0.35 \\
0.7 \\
\end{array}$ & & $\begin{array}{l}4.4 \\
5.3 \\
\end{array}$ & $\begin{array}{l}39200 \\
70000 \\
\end{array}$ & $\begin{array}{l}\mathrm{h} \\
\mathrm{f}\end{array}$ \\
\hline Tq-Ca-FLITS & $\begin{array}{l}\text { apo } \\
\text { sat }\end{array}$ & $\begin{array}{l}30600 \\
33700\end{array}$ & $\begin{array}{l}0.25 \\
0.75\end{array}$ & 360 & $\begin{array}{c}4.35 \\
4.71,5.91\end{array}$ & $\begin{array}{c}7650 \\
25275\end{array}$ & $\begin{array}{l}\text { This } \\
\text { study }\end{array}$ \\
\hline mTurquoise2 & & 30000 & 0.93 & & 3.6 & 27900 & $\mathrm{i}, \mathrm{j}$ \\
\hline
\end{tabular}



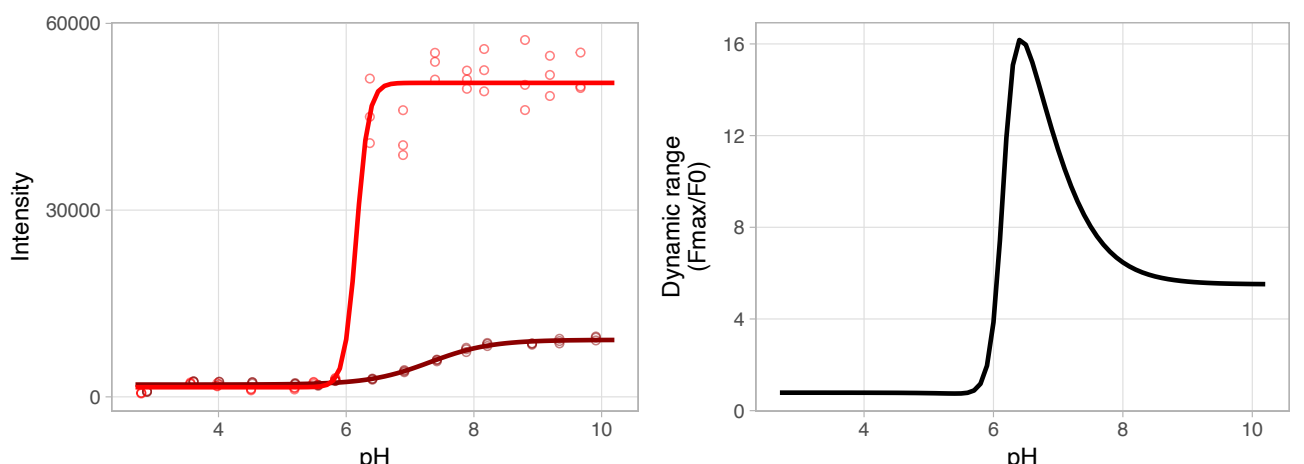

Figure S3. Intensity change of RCaMP1h as a response to $\mathbf{p H}$. Left panel: A Hill curve with one p $K_{a}$ value and Hill-coefficient was fitted through the measured data (circles, $n=3$ ) for the calcium bound (bright red) and unbound (gray) state, resulting in a $\mathrm{pK}_{\mathrm{a} \text {,sat }}$ of 6.2 and a $\mathrm{pK}_{\mathrm{a}, \text { apo }}$ of 7.3 Right panel: The calculated dynamic range was determined by division of the models fitted in the left panel.

Our aim was to engineer a new GECI using a single FP that displays a robust calciumdependent lifetime contrast, with sufficient brightness to accurately measure calcium concentrations across its full dynamic range. We used mTurquoise 2 as a template, since it has a high $Q Y$, high lifetime and we have a thorough understanding of residues that affects its $Q Y$ and lifetime ${ }^{33}$. In addition, the $\mathrm{p} K_{a}$ of mTurquoise 2 is $\operatorname{low}^{34}(\sim 3.6)$ and it is unlikely that a conformation change would affect the protonation state and $\varepsilon$.

Following the approach that led to the GECO series ${ }^{6}$, CaM and its binding peptide M13 were attached to new $\mathrm{N}$ - and C-termini of a circular permutated mTurquoise2 (cpTq2). Since information on circular permutated cyan fluorescent proteins is hardly available, we experimentally determined the optimal site for circular permutation of mTurquoise2. To this end, cpTq2 sensor variants were cloned into a new dual expression vector termed pFHL, which allows protein expression in mammalian cells and in the periplasm of Escherichia coli, and is suitable for isolation of the protein of interest (Supplementary note 1, Figure S4). Nine candidate sensors were constructed: seven with the new termini in the 7 th $\beta$-strand and the remaining two in the 10 th $\beta$-strand of the mTurquoise $2 \beta$ barrel (Figure 1A). Seven of the nine candidate sensors showed fluorescence in E. coli and HeLa cells. The sensor with the CaM and M13 attached to amino acids 149 and 150 respectively (which we named Tq-Ca-FLITS.0) showed about a 2-fold change in intensity in periplasmic fluid isolated from bacteria upon addition of calcium (periplasm test, Figure S5A), while the others showed little to no response. When expressed in HeLa cells, Tq-Ca-FLITS.0 showed a 3-fold intensity change upon addition of ionomycin (Figure 1B and S5B). We recorded the lifetime in both states of all seven candidate-sensors using frequency domain Fluorescence Lifetime Imaging Microscopy (FLIM). Tq-Ca-FLITS.0 
bioRxiv preprint doi: https://doi.org/10.1101/2021.06.21.449214; this version posted June 21, 2021. The copyright holder for this preprint (which was not certified by peer review) is the author/funder, who has granted bioRxiv a license to display the preprint in perpetuity. It is made available under aCC-BY-NC-ND 4.0 International license.

again showed the largest response, with a striking phase and modulation lifetime change of over 1 ns (Figure 1B-C and S5C). The other variants showed only marginal changes in lifetime.

A
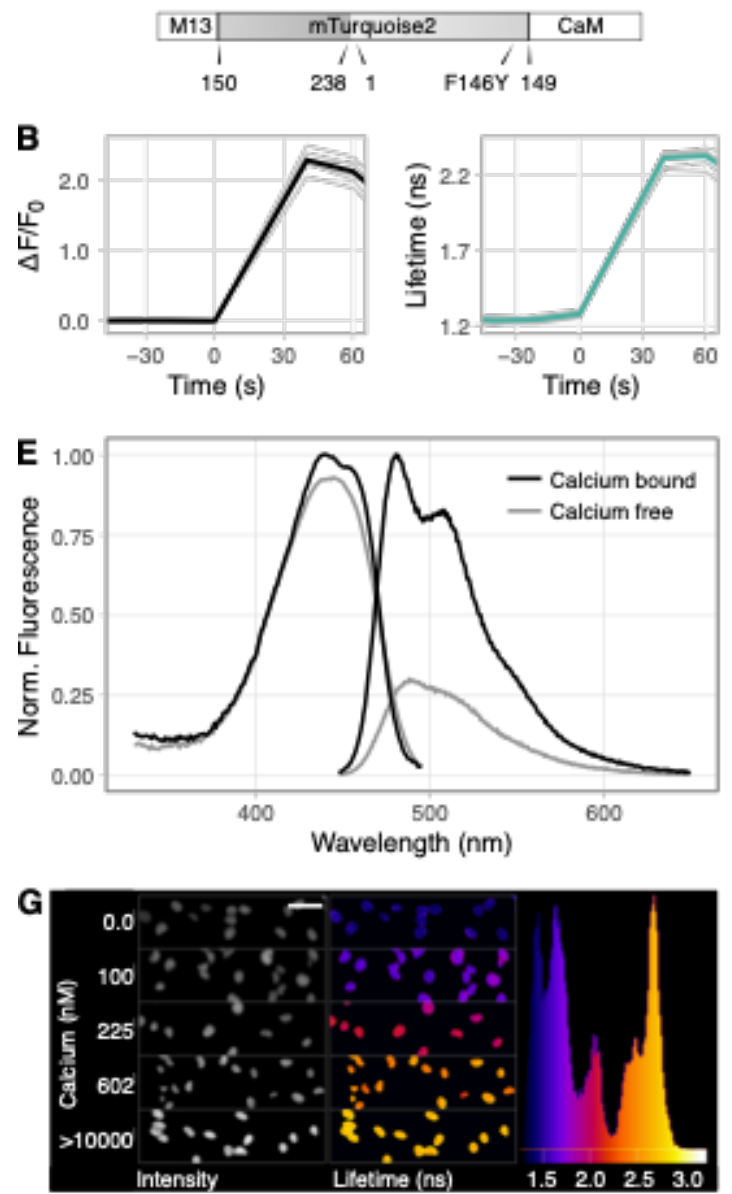
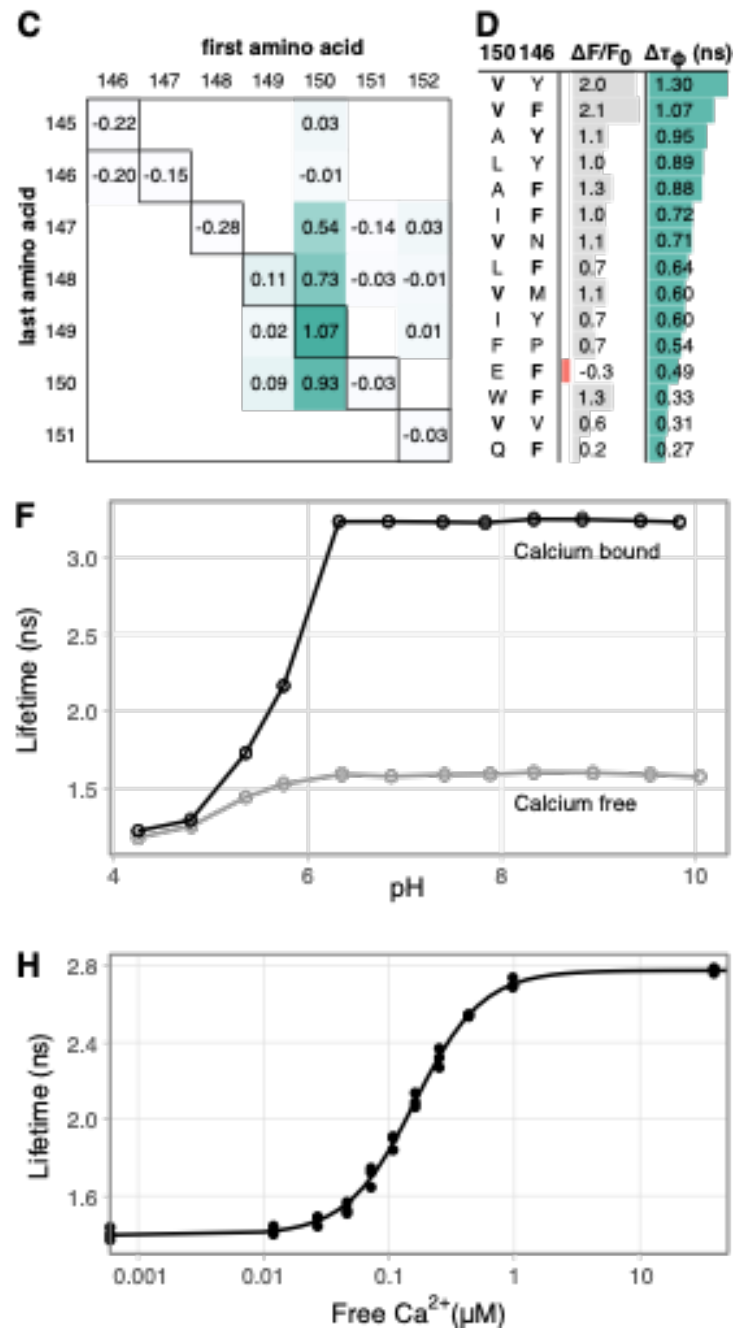

Figure 1. Development and characterization of the Turquoise calcium sensor. A) Schematic overview of the layout of Tq-Ca-FLITS, including key mutation F146Y. Positions of the original (amino acid 1 and 238) and the new (150 and 149) N- and C-termini are indicated. B) Intensity fold change over $F_{0}$ and phase lifetime response of Tq-Ca-FLITS.0 in HeLa cells stimulated with ionomycin and calcium at $t=0$. Responses of individual cells (gray, $n=7$ ) and their mean (black or green) are plotted. C) Absolute phase lifetime change of various sensor variants in HeLa cells stimulated with ionomycin and calcium. The first amino acid of mTurquoise 2 after the M13 peptide and the last amino acid before the CaM are indicated. On the diagonal axis (black outline) are the sensor variants that were created to find the ideal position to insert the CaM and the M13 peptide. The other variants contain 2 to 4 indels around the insertion site. Values are means of 2 to 23 individual cells. D) Intensity fold-change over $F_{0}$ and absolute phase lifetime change of mutants of Tq-Ca-FLITS.0 in HeLa cells stimulated with ionomycin and calcium. Amino acids at position 150 and 146 of mTurquoise are indicated. The original residues ( $\mathrm{V}$ and $\mathrm{F}$ ) are printed in bold. Values are means of 2 to 10 individual cells. E) Normalized absorbance and emission spectra of Tq-Ca-FLITS in vitro for the calcium bound and unbound state. F) Tq-Ca-FLITS is pH insensitive from $\mathrm{pH} 6.2$ onwards, as shown by the phase lifetime of the calcium bound and unbound states in vitro ( $n=3$ with line average). G) The phase lifetime of Tq-Ca-FLITS stabilizes in HeLa cells during the in vivo calibration. The endpoint of 5 concentrations is shown. Visual display is generated by an ImageJ macro ${ }^{35}$. Scale bar is $50 \mu \mathrm{m}$. H) Calibration curve of the phase lifetime in vivo, with the calcium concentration on a logarithmic scale $(n=3)$. 
A

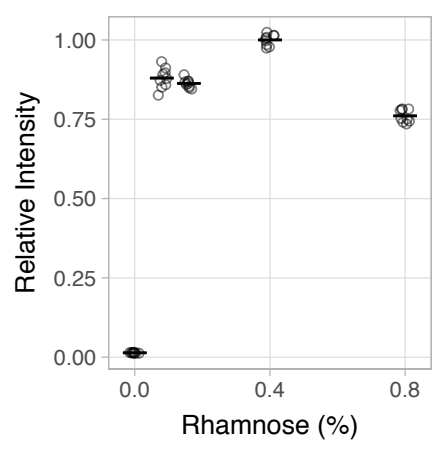

B

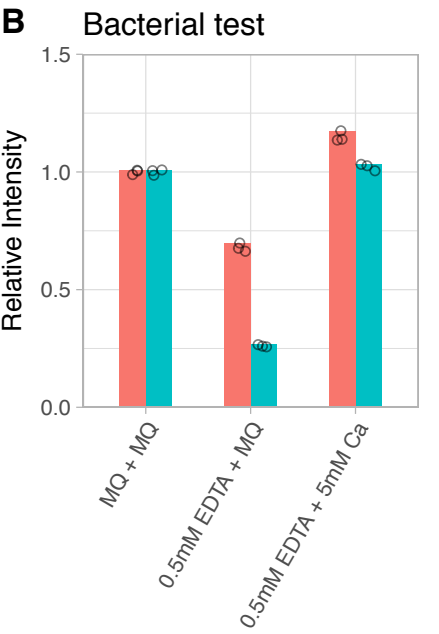

Periplasm test

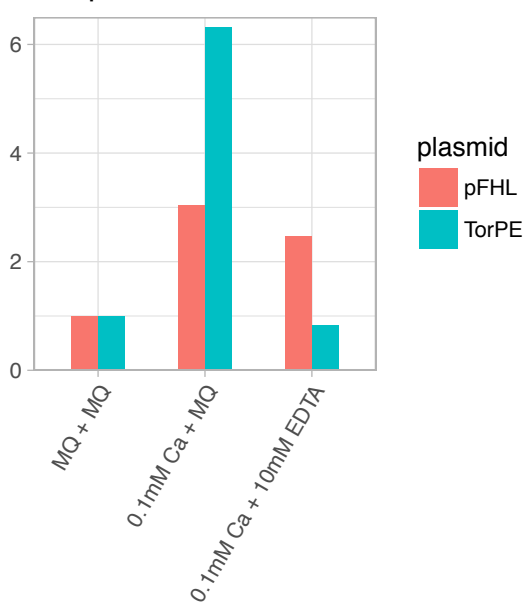

Figure S4. Verification of the new dual expression plasmid named pFHL. A) Normalized fluorescence intensities are shown of overnight grown E. coli cultures expressing R-GECO1 at different rhamnose concentrations, using the $\mathrm{pFHL}$ vector that contains a rhamnose promotor. Separate measurements (circles, $n=9$ ) and the mean are indicated. B) R-GECO1 responds to changing calcium concentrations in E. coli (Bacterial test, $n=3$ ) and in isolated periplasmic fluid (Periplasm test, $n=1$ ), by sequential addition of calcium and chelator EDTA. MilliQ water (MQ) was used a control. The performance of the pFHL vector in this test was compared to the pTorPE vector.

A $F_{\max } / F_{\min }$ in periplasmic fluid first amino acid

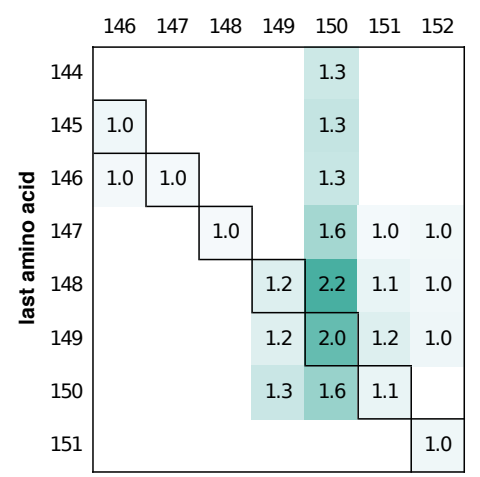

B $\mathrm{F}_{\mathrm{max}} / \mathrm{F}_{0}$ in HeLa cells

first amino acid

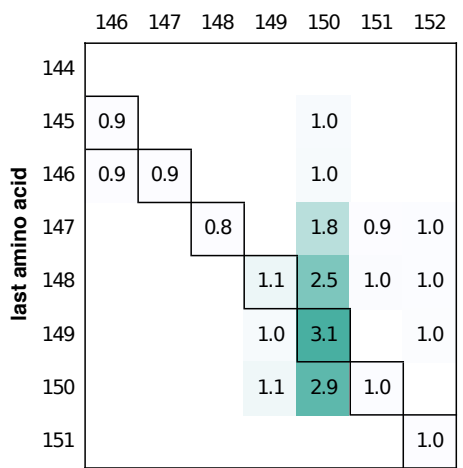

C $\Delta \tau_{\mathrm{M}}$ in HeLa cells

first amino acid

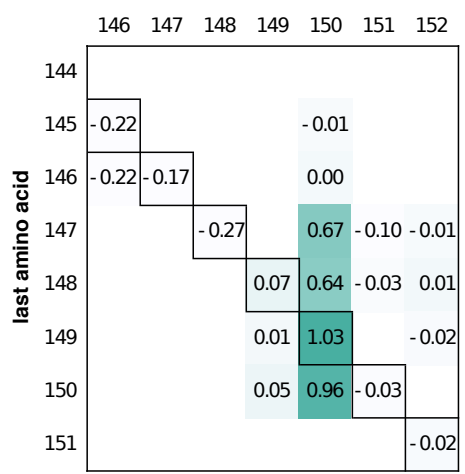

Figure S5. Screening the insertion site and the number of indels for the creation of Tq-Ca-FLITS. A) Intensity fold-change of different sensor variants in periplasmic shock fluid isolated from E. coli. B) Intensity fold-change and $\mathbf{C}$ ) absolute modulation lifetime change (ns) in HeLa cells upon stimulation with ionomycin and calcium. In all panels are the first amino acid of mTurquoise2 after the M13 peptide and the last amino acid before the CaM indicated. See also the design of Tq-Ca-FLITS in Figure 1A. On the diagonal axis (black boxes) are the sensor variants that were created to find the ideal position to insert the CaM and the M13 peptide (mean of 8 to 23 cells). The other variants contain 2 to 5 indels around the insertion site (mean of 2 to 8 cells).

Next, we set out to improve our sensor by creating variants with up to 2 insertions or 5 deletions on both sides of the cpTq2, however this did not result in an improvement (Figure S5). Tq-Ca-FLITS.0 was therefore subjected to mutagenesis on two key residues that affect the fluorescence lifetime, i.e. F146 and V150 (original mTq2 numbering). F146 was previously shown to have a large influence on the lifetime of mTurquoise $2^{33}$. V150 was selected for its position with respect to the chromophore, and in a small screen it 
bioRxiv preprint doi: https:/doi.org/10.1101/2021.06.21.449214 this version posted June 21, 2021. The copyright holder for this preprint (which was not certified by peer review) is the author/funder, who has granted bioRxiv a license to display the preprint in perpetuity. It is made available under aCC-BY-NC-ND 4.0 International license.

showed to have an influence on the lifetime of mTurquoise2 (Supplementary note 2,

Figure S6).

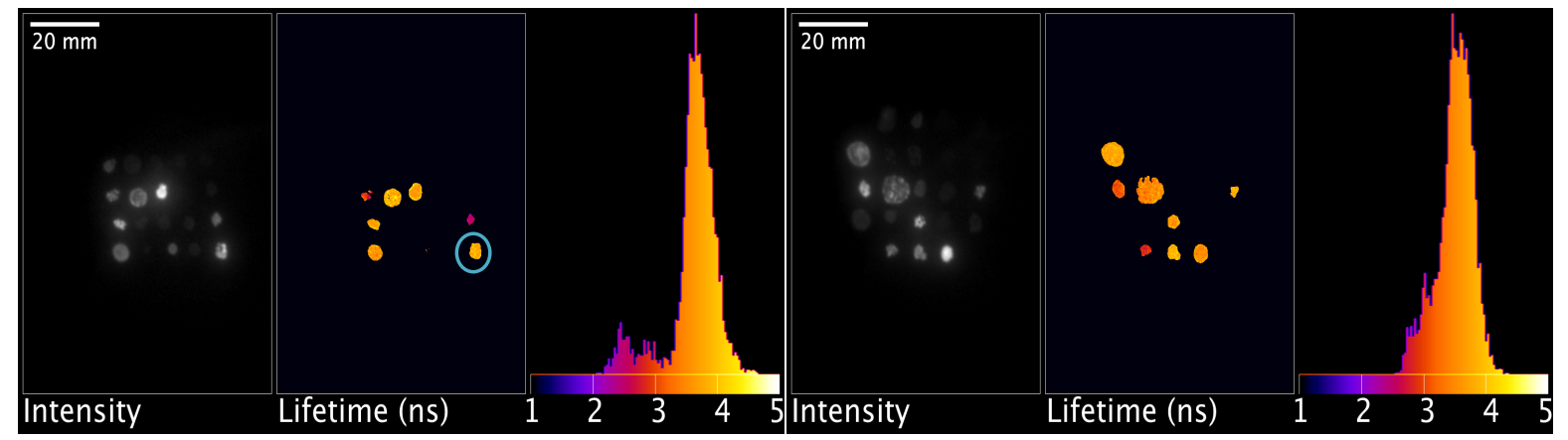

Figure S6. Lifetimes displayed by mTurquoise 2 mutants in $\boldsymbol{E}$. coli on agar plates. Intensity and modulation lifetime of mTurquoise2 mutated at position V150 are displayed. Two agar plates were imaged. A histogram of the modulation lifetimes is shown for each plate. A circle indicates non-mutated mTurquoise2. The panel was generated by an imageJ macro ${ }^{35}$.

A library of Tq-Ca-FLITS.0 containing F146X and/or V150X mutation(s) was initially screened in E. coli on agar plates, selecting for colonies showing a high intensity. We noticed that the sensors under these conditions are primarily in the high lifetime and high intensity state (Supplementary note 3, Figure S7). By selecting the high lifetime colonies we aimed to increase the overall brightness of the probe and increase the lifetime of the calcium bound state. Over 450 colonies were screened of which 60 'high' intensity colonies were selected, and 17 'low' and 16 'intermediate' colonies as control. The selected colonies were screened in liquid bacterial culture, by monitoring the change in fluorescence intensity upon addition of calcium chelator EDTA to the culture. The periplasmic fluid of the best performing candidates was isolated for further testing (with the periplasm test) and their DNA sequence was determined.

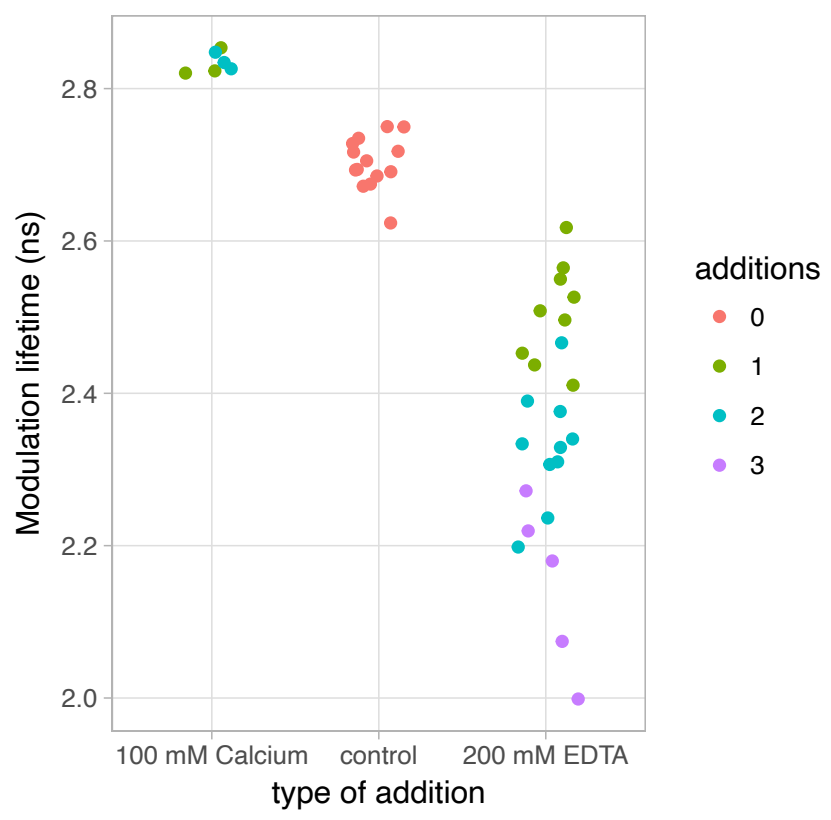

Figure S7. Modulation lifetime of bacterial colonies expressing Tq-Ca-FLITS.0. Colonies were stimulated 1, 2 or 3 times with a droplet of $100 \mathrm{mM}$ calcium or $200 \mathrm{mM}$ EDTA. Calcium increases the modulation lifetime and each drop of EDTA decreases the lifetime. 
bioRxiv preprint doi: https://doi.org/10.1101/2021.06 21.449214 this version posted June 21,2021 . The copyright holder for this preprint (which was not certified by peer review) is the author/funder, who has granted bioRxiv a license to display the preprint in perpetuity. It is made available under aCC-BY-NC-ND 4.0 International license.

Optimal responses were observed when amino acids at position 150 were $\mathrm{V}$ or $\mathrm{A}$, and $\mathrm{F}$ or Y at position 146 (Figure S8). Based on these results five additional variants were constructed, with I, L or A at position 146 and F or Y at position 150. The designed variants and the top candidates from the screen were tested in HeLa cells for lifetime contrast (Figure 1D). We identified a new variant with a F146Y mutation that showed a comparable intensity response as the original variant and an increased phase lifetime response of about 1.3 ns. This variant was named Tq-Ca-FLITS, for Turquoise Calcium Fluorescence LIfeTime Sensor.

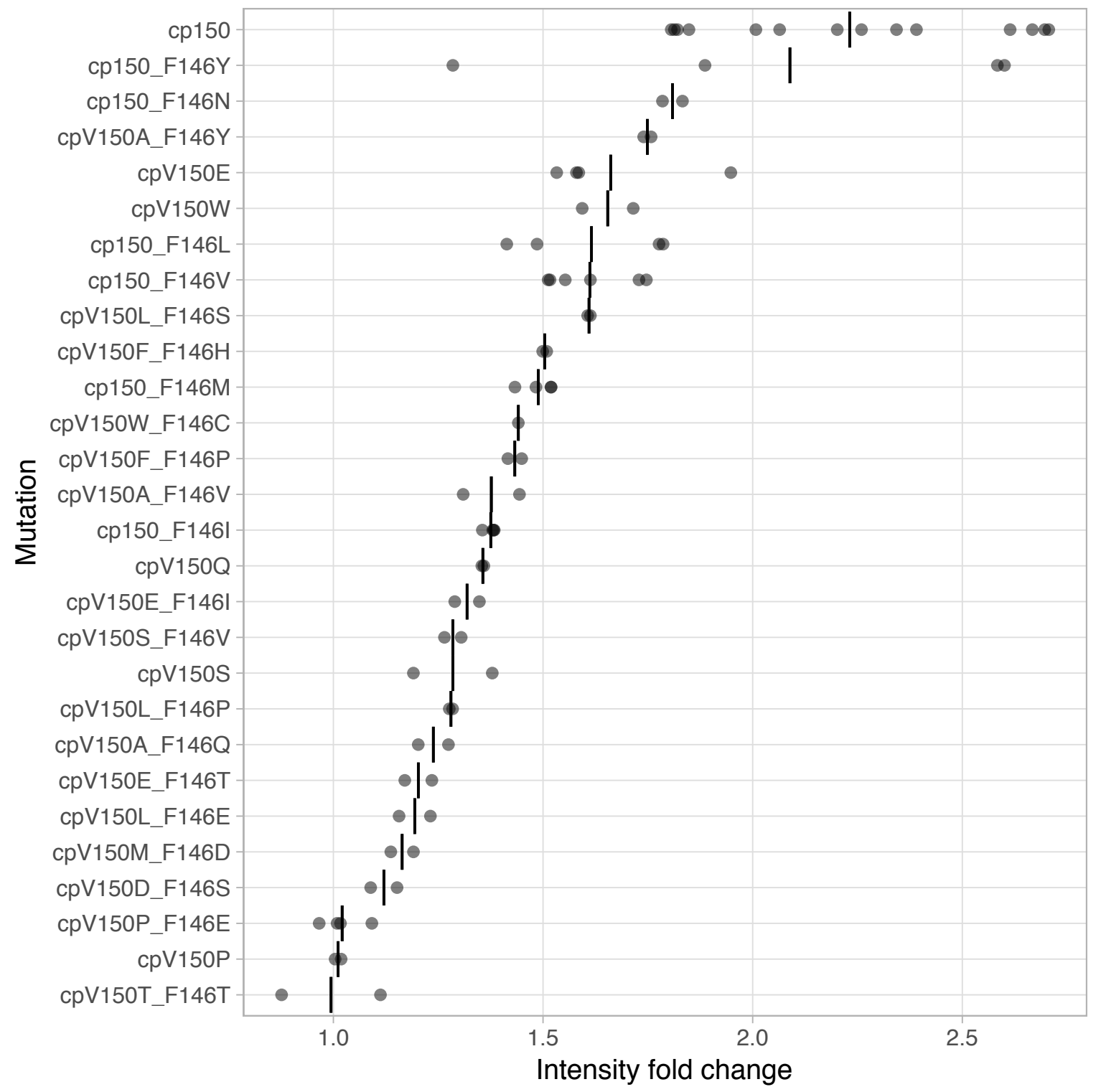

Figure S8. Intensity fold-change $\left(F_{\max } / F_{0}\right)$ of mutant sensors as measured by the periplasmic test. Gray circles indicate individual experiments and black lines indicate the means per mutant. The original amino acids at position 150 and 146 are $\mathrm{V}$ and $\mathrm{F}$. 
bioRxiv preprint doi: https://doi.org/10.1101/2021.06.21.449214 this version posted June 21 2021. The copyright holder for this preprint (which was not certified by peer review) is the author/funder, who has granted bioRxiv a license to display the preprint in perpetuity. It is made available under aCC-BY-NC-ND 4.0 International license.

In vitro characterization of Tq-Ca-FLITS showed a substantial difference in quantum yield between the calcium bound and calcium free state ( $75 \%$ and $25 \%$ respectively), which is in line with the lifetime change. The extinction coefficient between the two states is comparable, unlike virtually all 'GCaMPs'3,23 (Table 1 and S3, Figure S9).

\section{A Absorbance and Emission}

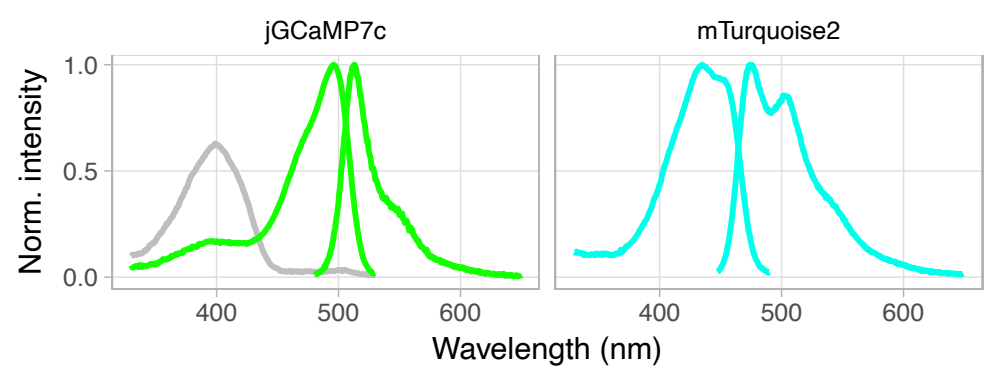

\section{B Unfolding of Tq-Ca-FLITS}

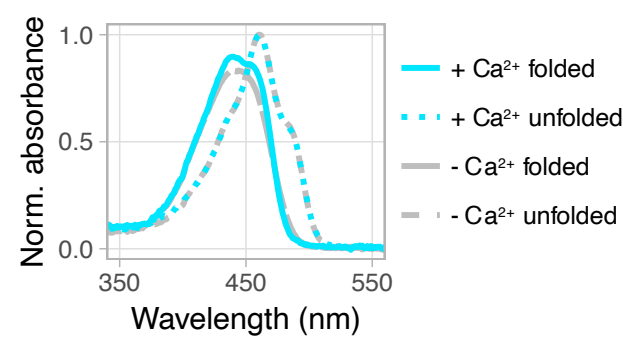

Figure S9. Properties of Tq-Ca-FLITS and jGCaMP7c in vitro. A) Absorption and excitation spectra of: jGCaMP7c (left panel) in the calcium bound (green) and unbound state (gray) and mTurquoise2 (right panel). B) Change in absorbance spectra of Tq-Ca-FLITS by unfolding the calcium bound (blue) and unbound (gray) state with $1 \mathrm{M} \mathrm{NaOH}$.

Table 1. Properties of Tq-Ca-FLITS

\begin{tabular}{|c|c|c|c|c|c|c|c|c|c|c|c|}
\hline & \multicolumn{5}{|c|}{ Spectral properties } & \multicolumn{3}{|c|}{ Intensity data } & \multicolumn{3}{|c|}{ Lifetime data } \\
\hline & $\begin{array}{l}\lambda_{a b s} \\
(\mathrm{~nm})\end{array}$ & $\begin{array}{l}\lambda_{e m} \\
(\mathrm{~nm})\end{array}$ & $Q Y$ & $\begin{array}{c}\varepsilon \\
\left(\mathrm{mM}^{-1}\right. \\
\left.\mathrm{cm}^{-1}\right)\end{array}$ & $\mathrm{p} K_{a}[n]$ & $\begin{array}{c}K_{d}[n] \\
(\mathrm{nM}) \\
\mathrm{pH} 7.2\end{array}$ & $\begin{array}{c}F_{\max } / F_{\min } \\
\text { in vitro } \mathrm{pH} \\
7.0\end{array}$ & $\begin{array}{l}F_{\max } / F_{0} \\
\text { in vivo }\end{array}$ & $\begin{array}{c}\tau_{\varphi} \\
\text { (ns) }\end{array}$ & $\begin{array}{c}\tau_{M} \\
\text { (ns) }\end{array}$ & $\begin{array}{c}K_{d}[n] \\
(\mathrm{nM})\end{array}$ \\
\hline Apo & 442 & 489 & 0.25 & 30.6 & $4.35[0.86]$ & & & & 1.40 & 1.80 & \\
\hline Sat & 439 & 481 & 0.75 & 33.7 & $\begin{array}{l}1: 4.71[0.70] \\
2: 5.91[3.58]\end{array}$ & $360[1.51]$ & 3.51 & 3.02 & 2.78 & 3.01 & 265 [1.63] \\
\hline
\end{tabular}

Spectral properties: $\lambda_{a b s}-$ Absorbance maximum. $\lambda_{e m}-$ Emission maximum. $Q Y-$ Quantum Yield relative to mTurquoise2. $\varepsilon$ - Extinction coefficient at $440 \mathrm{~nm}$. $\mathrm{p} K_{a}[n]-$ Apparant $\mathrm{p} K_{a}$ value, with the Hill coefficient $[n]$ between brackets. A model with two $\mathrm{p} K_{a}$ values was used for the calciumsaturated state.

Intensity: $K_{d}[n]$ - Apparent $K_{d}$ in vitro, with the Hill coefficient $[n]$ between brackets. $F_{\max } / F_{\min }-$ ratio of maximum over minimum fluorescence intensity, or fluorescence of calcium bound state over calcium unbound state. $F_{\max } / F_{0}$ - maximum intensity over starting intensity in vivo, as determined by stimulation with ionomycin and calcium.

Lifetime: quantitative in vivo readout with $\tau_{\varphi}$ - phase lifetime. $\tau_{M}$ - Modulation lifetime. $K_{d}[n]-$ Apparent $K_{d}$, with the Hill coefficient [ $n$ ] between brackets, determined from the position of the lifetimes on a polar plot. 
Table S3. Properties of Tq-Ca-FLITS compared to jGCaMP7c and mTurquoise2

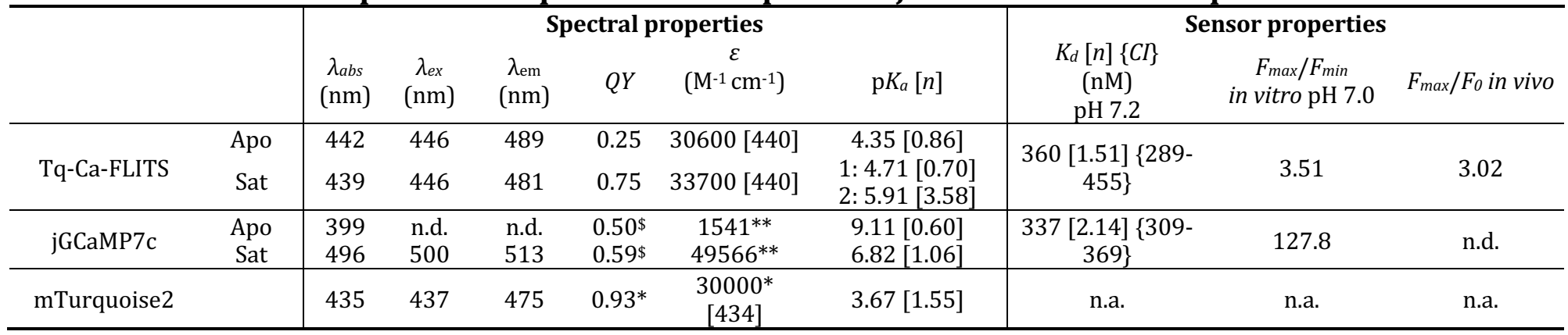

Spectral properties: $\lambda_{a b s}-$ Absorbance maximum. $\lambda_{e x}-$ Excitation maximum. $\lambda_{e m}-$ Emission maximum. $Q Y$ - Quantum Yield relative to mTurquoise2. $\varepsilon$ - Extinction coefficient, determined at the indicated wavelength. $\mathrm{p} K_{a}[n]-$ Apparant $\mathrm{p} K_{a}$ values, with Hill coefficient [n]. A model with two $\mathrm{p} K_{a}$ values was used for the calcium saturated state of Tq-Ca-FLITS.

Sensor properites: $K_{d}[n]$ - Apparent $K_{d}$, with the Hill coefficient $[n]$ and the $95 \%$ confidence interval $\{C I\}$ indicated. $F_{\max } / F_{\min }$ - ratio of maximum over minimum fluorescence intensity, or calcium bound state over calcium unbound state in vitro. $F_{\max } / F_{0}$ - maximum intensity over starting intensity in vivo, as determined by stimulation with ionomycin and calcium $(n=3)$.

n.a./n.d.: not applicable/not determined.

* Determined earlier in our lab ${ }^{33}$

** Published by others ${ }^{3}$
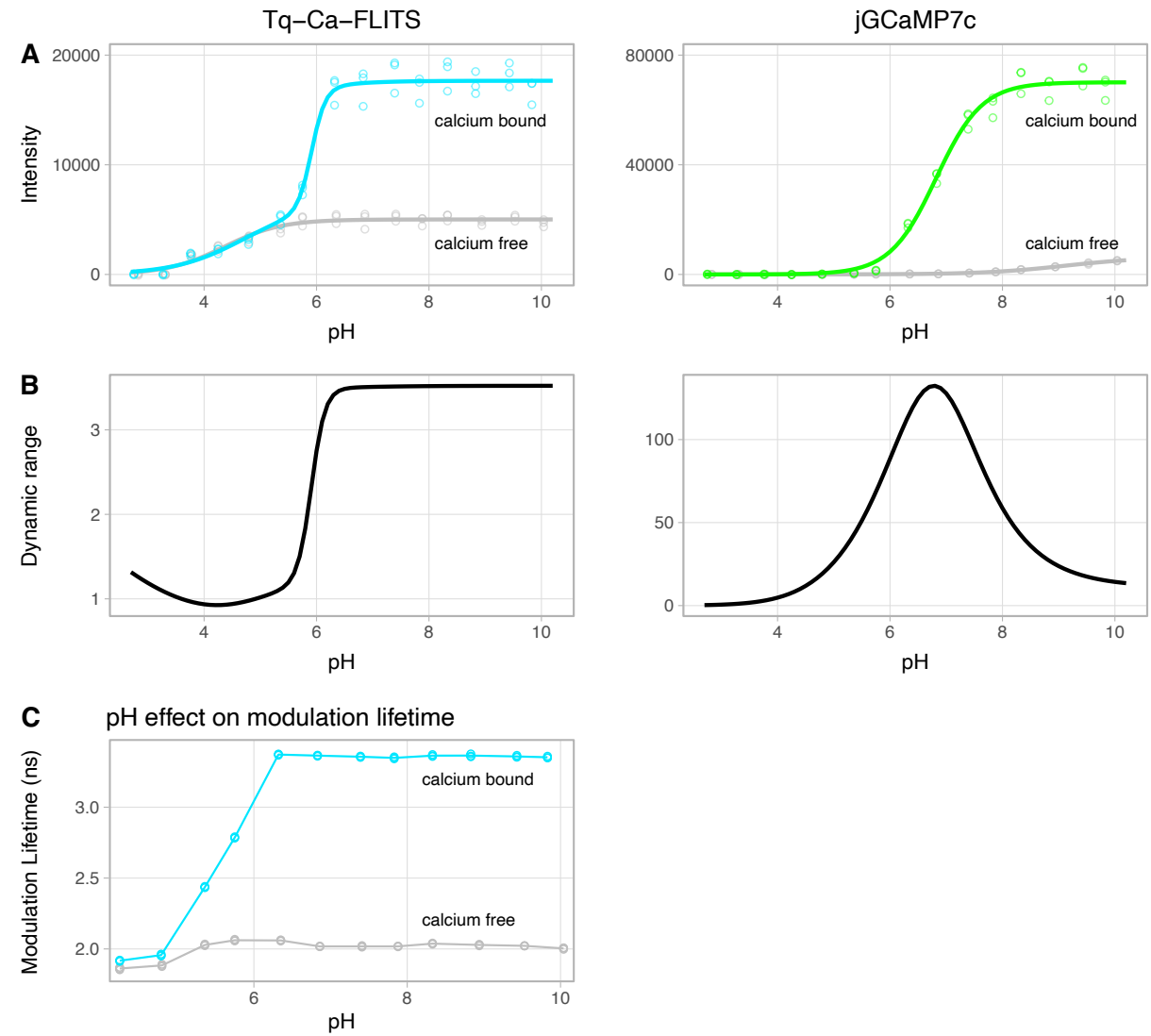

Figure S10. pH sensitivity of Tq-Ca-FLITS and jGCaMP7c in vitro. A) Intensity change of both sensors as a response to $\mathrm{pH}$, for the calcium bound (blue/green) and unbound (gray) state (all $n=3$ ). A Hill curve (line) with one $\mathrm{p} K a$ value and Hill-coefficient was fitted through the measured data (circles), except for calcium bound Tq-Ca-FLITS where a model with two $\mathrm{pK} a$ values was used. B) The dynamic range of Tq-Ca-FLITS is stable in the biological pH range, while it fluctuates strongly for jGCaMP7c. The dynamic range is calculated as a ratio of the models presented in panel A. C) The modulation lifetime of Tq-Ca-FLITS is stable above $\mathrm{pH}$ $6.2(n=3$, with line average). 
bioRxiv preprint doi: https:/doi.org/10.1101/2021.06.21.449214 this version posted June 21, 2021. The copyright holder for this preprint (which was not certified by peer review) is the author/funder, who has granted bioRxiv a license to display the preprint in perpetuity. It is made available under aCC-BY-NC-ND 4.0 International license.

The $\mathrm{pH}$ and magnesium sensitivity of Tq-Ca-FLITS were investigated and compared to jGCaMP7c. Strikingly, both lifetime and intensity of Tq-Ca-FLITS are insensitive to $\mathrm{pH}$ above pH 6.2, making it a robust probe for biological measurements (Figure 1F and S10). Using the intensity data, we determined a $\mathrm{p} K_{a, a p o}$ of 4.35 (Hill coefficient 0.86 ) for the free, unbound state of Tq-Ca-FLITS. A model with two $\mathrm{p} K_{a}$ values was used for the calcium bound state, and resulted in a $\mathrm{p} K_{a, s a t, 1}$ of 4.71 (Hill coefficient 0.70 ) and a p $K_{a, s a t, 2}$ of 5.91 (Hill coefficient 3.58) (Table 1 and S3). The low and very similar $\mathrm{p} K_{a, a p o}$ and $\mathrm{p} K_{a, s a t, 1}$ are likely a direct result of the pH dependency of the fluorescent protein in Tq-Ca-FLITS. The $\mathrm{p} K_{a, s a t, 2}$ probably shows the $\mathrm{pH}$ sensitivity of the four calcium binding domains of the CaM, which is also supported by the high Hill coefficient ${ }^{36}$. This $\mathrm{p} K_{a, s a t, 2}$ corresponds with the isoelectric point of CaM binding domains, which is shown to be around $6^{37}$. As expected, jGCaMP7c showed a clear pH sensitivity in the biological range.

We found a very low magnesium sensitivity for Tq-Ca-FLITS, both in intensity and lifetime readout (Figure S11). However, jGCaMP7c does show a marked change in dynamic range at the low magnesium concentrations (below $1 \mathrm{mM}$ ), which is reported to be right in the biological range ${ }^{38}$.

A
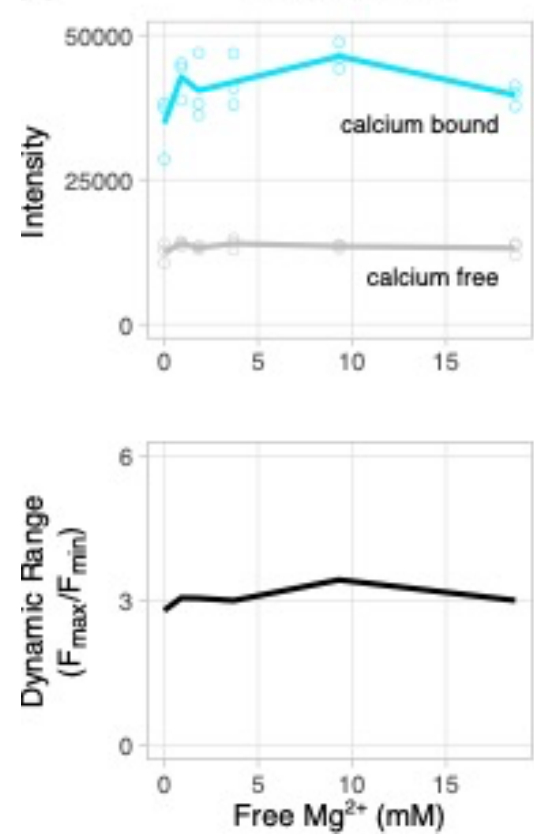

jGCaMP7c
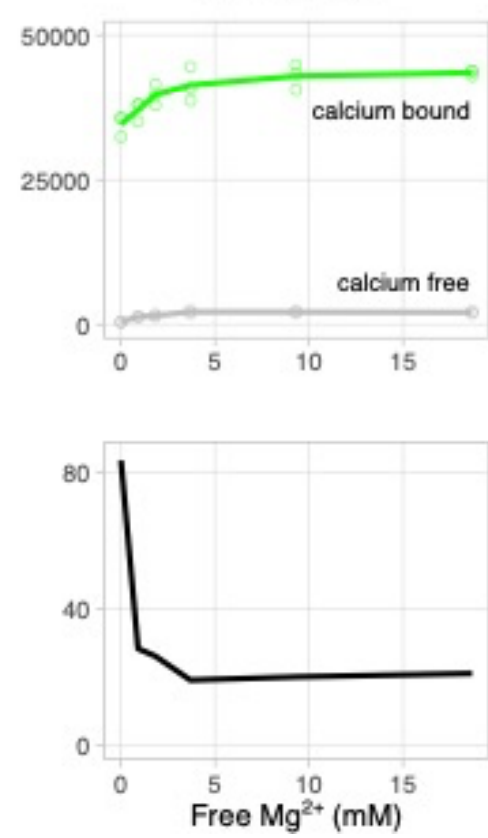

B Lifetime Tq-Ca-FLITS
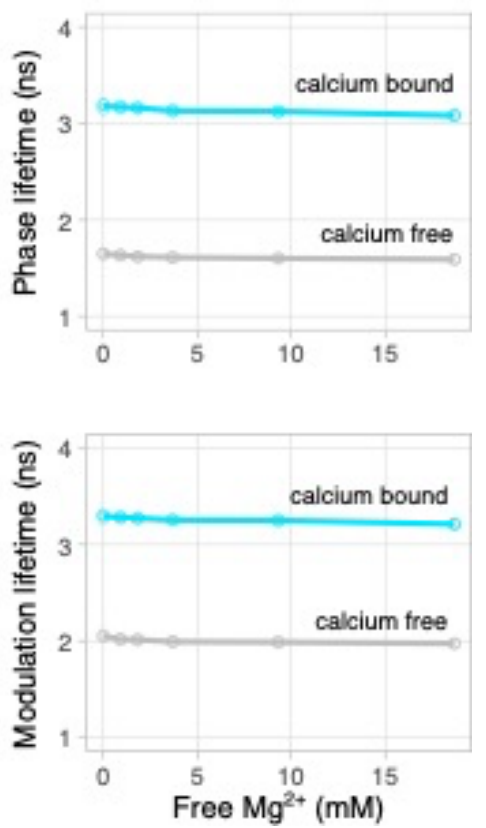

Figure S11. Magnesium sensitivity of Tq-Ca-FLITS and jGCaMP7c in vitro. A) Fluorescence intensity for the calcium bound (blue/green) and free (gray) state (top panels), and the corresponding dynamic range (bottom panels). B) Phase and modulation lifetime of Tq-Ca-FLITS in response to magnesium, for both the calcium bound (blue) and free (gray) state. Individual measurements $(n=3)$ are indicated by dots, the line represents the average. 
bioRxiv preprint doi: https://doi.org/10.1101/2021.06.21.449214; this version posted June 21, 2021. The copyright holder for this preprint (which was not certified by peer review) is the author/funder, who has granted bioRxiv a license to display the preprint in perpetuity. It is made available under aCC-BY-NC-ND 4.0 International license.

The intensity independent and quantitative readout of Tq-Ca-FLITS in combination with its specificity makes the sensor ideally suited for in vivo calibration ${ }^{39}$. To this end we established a HeLa cell line with stable expression of the sensor in the nucleus. Cells were incubated in calcium buffers and the calcium concentration in the cytoplasm was equilibrated with the outer environment by permeabilization of the membrane with digitonin. The concentration of calcium is plotted against the lifetime that was measured when equilibrium was reached (Figure 1G-H, Movie S1).

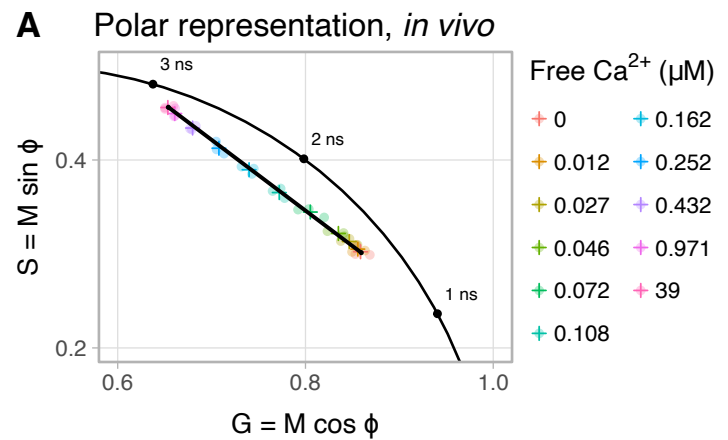

B Fraction in high lifetime state, in vivo
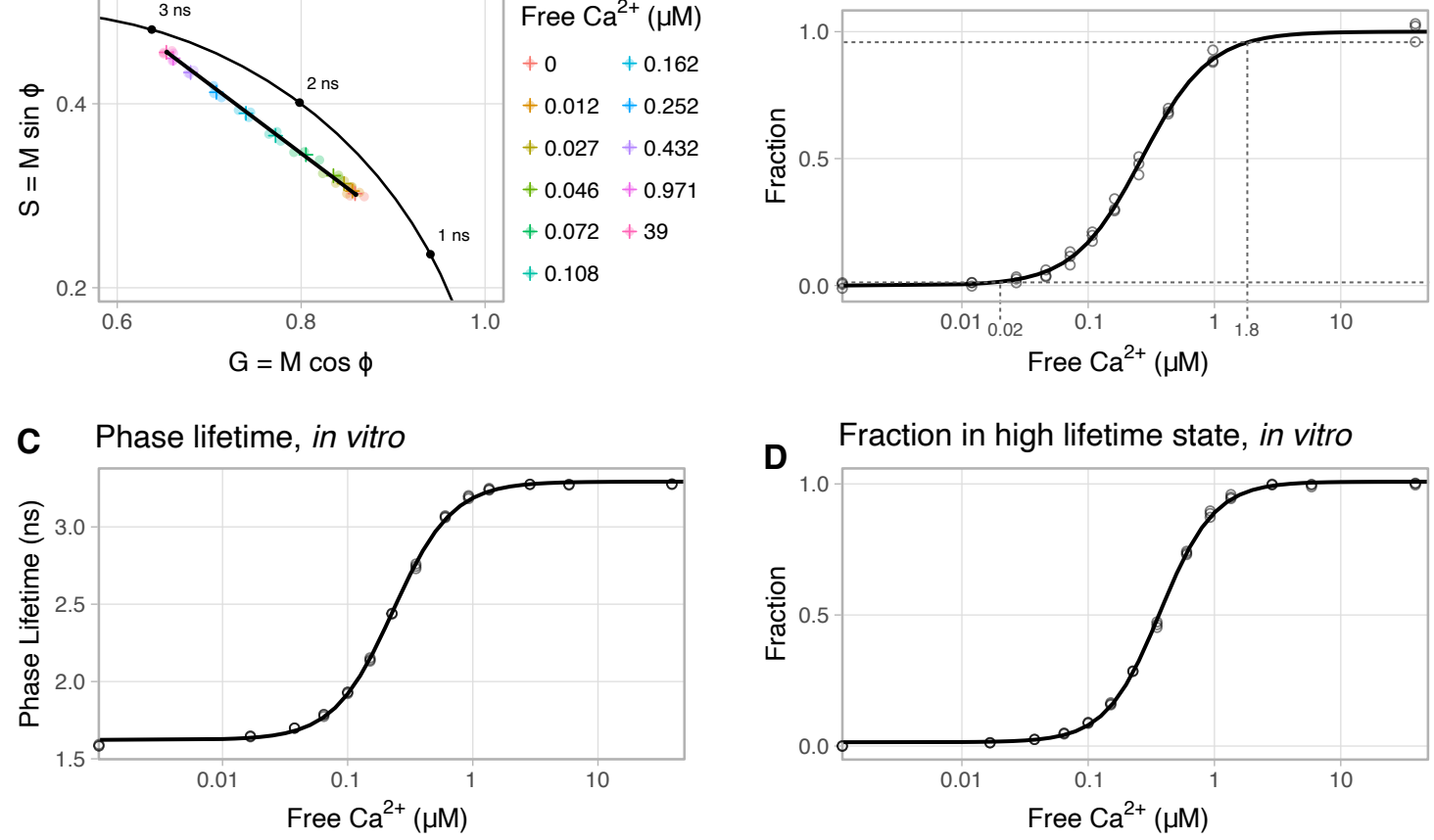

E Intensity Tq-Ca-FLITS, in vitro

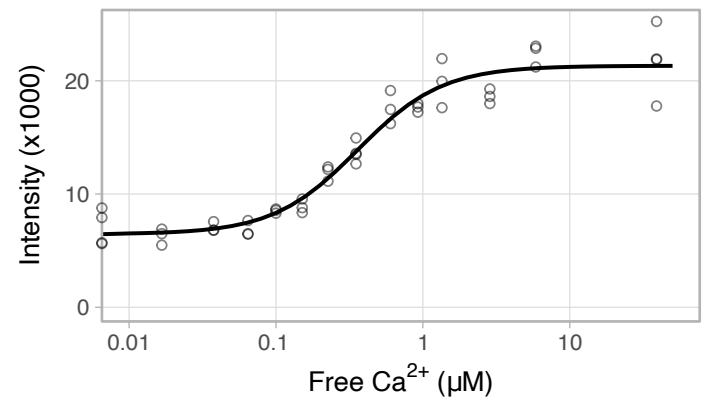

F Intensity jGCaMP7c, in vitro

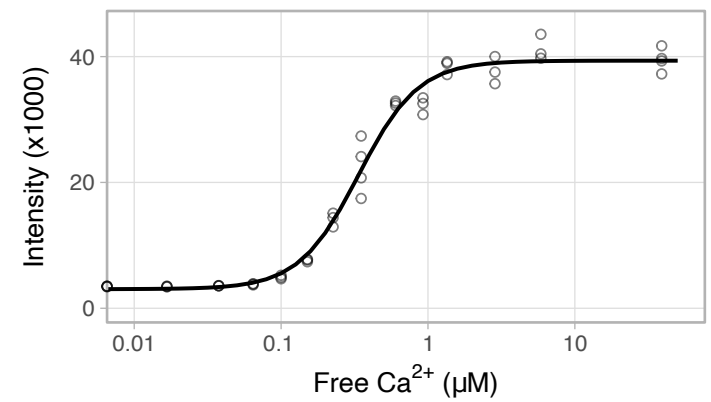

Figure S12. Calcium sensitivity of Tq-Ca-FLITS and jGCaMP7c. A) In vivo calibration of Tq-Ca-FLITS represented on a polar plot $(n=3)$, where ' $M$ ' and ' $\Phi$ ' relate to the modulation and phase lifetime, respectively. Each dot represents the average of all pixels in a view with $>20$ cells. The black line runs from the position of the calcium free state to the position of the calcium bound state. The fraction of sensor in the high state for each concentration was calculated from a projection on the black line, corrected for the intensity contribution of the two states. B) In vivo calibration of the fraction of Tq-Ca-FLITS in the high state as determined from a polar plot in panel $A(n=3)$. The dotted horizontal lines indicate the borders of the measurable range, based on the $95 \%$ confidence interval of the fraction of the lowest and highest calcium concentrations. C) In vitro calibration of the phase lifetime of Ta-Ca-FLITS $(n=3)$. D) In vitro calibration of the fraction of Tq-Ca-FLITS in the high state as determined from a polar plot (n=3). E and F) Sensitivity of the intensity readout of Tq-Ca-FLITS and jGCaMP7c in vitro (each $n=3$ ). In panels $\mathbf{B}-\mathbf{F}$ the circles indicate individual measurements, and the line represents the fitted model. In all figures the calcium concentration is plotted on a logarithmic scale. 
We converted the phase and modulation lifetime values of all calibration experiments to polar coordinates ${ }^{40}$, which resulted in a straight line on a polar (or phasor) plot (Figure S12A). For each calcium concentration we calculated the fraction of the sensor in the high lifetime state. This resulted in an apparent $K_{d}$ of $265 \mathrm{nM}$, which is comparable to the GCaMP6 series ${ }^{41}$ (Table 1 and S4, Figure S12B). The apparent $K_{d}$ in vitro was determined to be $372 \mathrm{nM}$, using isolated Tq-Ca-FLITS and applying a similar calculation on the lifetime data as for the in vivo calibration (Table S4, Figure S12C-D). When using the intensity data of the in vitro calibration, we found a similar apparent $K_{d}$ of $360 \mathrm{nM}$ (Table 1 and S3, Figure S12E). This is comparable to the apparent $K_{d}$ in vitro of R-GEC01, the parent of TqCa-FLITS ${ }^{6}$. Using the variation of the in vivo calibration we determined the detection range of the sensor to be $20 \mathrm{nM}-1.8 \mu \mathrm{M}$ (Figure S12B).

Table S4. Lifetime properties of Tq-Ca-FLITS for quantitative measurements

\begin{tabular}{c|ccc|ccc}
\hline & \multicolumn{3}{|c|}{ In vitro calibration } & \multicolumn{3}{c}{ In vivo calibration } \\
& $\tau_{\varphi}\{C l\}$ & $\tau_{M}\{C l\}$ & $K_{d}[n]\{C l\}$ & $\tau_{\varphi}\{C l\}$ & $\tau_{M}\{C l\}$ & $K_{d}[n]\{C l\}$ \\
& $(\mathrm{ns})$ & $(\mathrm{ns})$ & $(\mathrm{nM})$ & $(\mathrm{ns})$ & $(\mathrm{ns})$ & $(\mathrm{nM})$ \\
\hline \multirow{2}{*}{ Apo } & 1.62 & 1.97 & & 1.40 & 1.80 & \\
& $\{1.61-1.64\}$ & $\{1.96-1.98\}$ & $372[2.03]$ & $\{1.37-1.42\}$ & $\{1.75-1.86\}$ & $265[1.63]$ \\
\multirow{2}{*}{ Sat } & 3.29 & 3.35 & $\{364-380\}$ & 2.78 & 3.01 & $\{257-274\}$ \\
& $\{3.28-3.30\}$ & $\{3.34-3.36\}$ & & $\{2.74-2.81\}$ & $\{2.96-3.07\}$ & \\
\hline
\end{tabular}

$\tau_{\varphi}$ - phase lifetime. $\tau_{M}$ - Modulation lifetime. $K_{d}[n]$ - Apparent $K_{d}$, with the Hill coefficient [n], determined from the position on a polar plot. $95 \%$ confidence intervals $\{C l\}$ are indicated.

To enable detection in various cellular compartments, we generated probes that localize in the cytoplasm, at the Golgi apparatus or at the plasma membrane (Figure S13). Next, we examined the performance of the Tq-Ca-FLITS probe for quantitative intracellular calcium imaging in a number of biological systems. It has been well established that primary endothelial cells (ECs) respond to histamine with a transient intracellular calcium release $\mathrm{e}^{42}$. We quantified the calcium levels after stimulation with $1 \mu \mathrm{M}$ histamine and observed spatial heterogeneity of the calcium distribution, proving that Tq-Ca-FLITS is suitable for local quantification of intracellular calcium (Figure 2A-B, Movie S2).
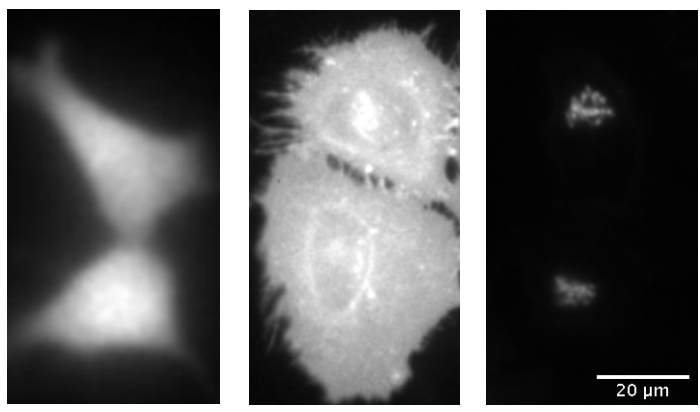

Figure S13. Organelle targeting of Tq-Ca-FLITS.

The probe localizes to the cytoplasm without a targeting sequence (left panel), to the plasma membrane using an Lck-tag (middle panel), and the Golgi using a giantin-tag (right panel). All panels show two cells. 
bioRxiv preprint doi: https://doi.org/10.1101/2021.06.21.449214; this version posted June 21, 2021. The copyright holder for this preprint (which was not certified by peer review) is the author/funder, who has granted bioRxiv a license to display the preprint in perpetuity. It is made available under aCC-BY-NC-ND 4.0 International license.
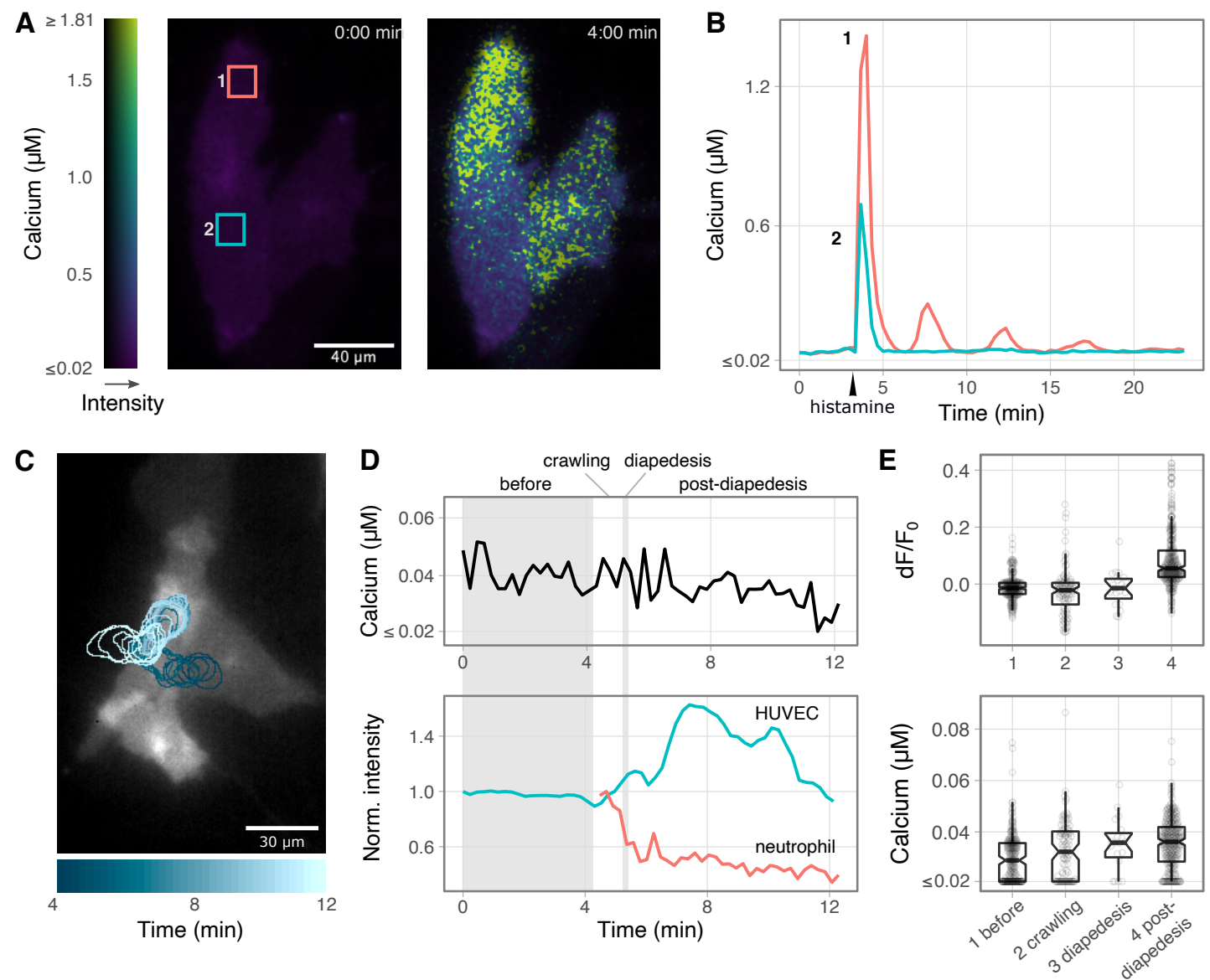

$\mathbf{F}$
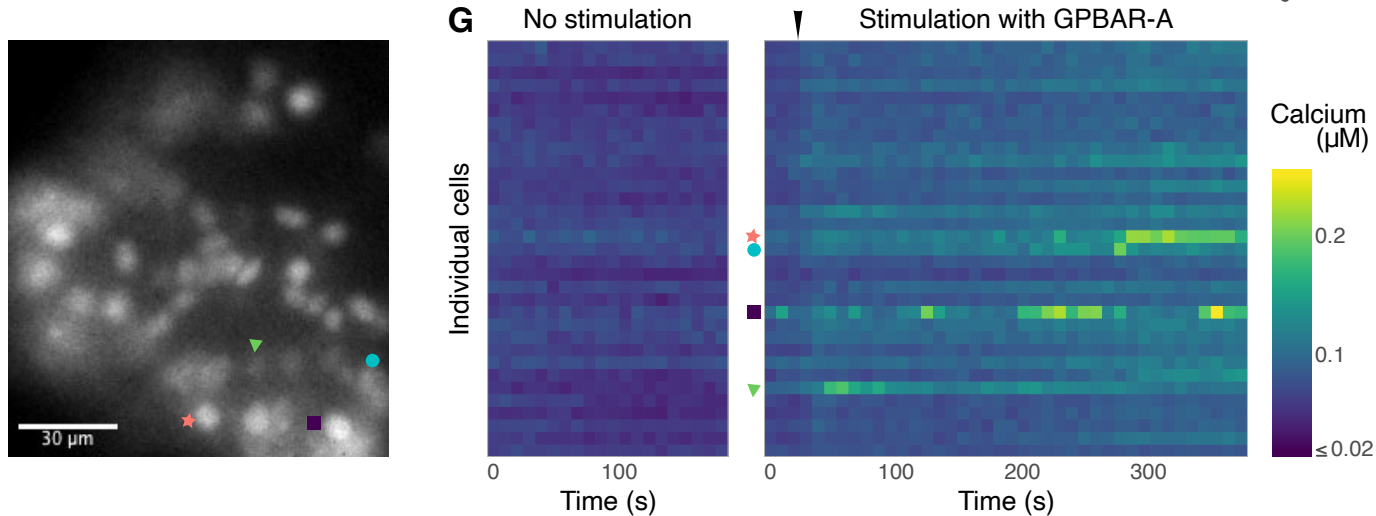

Figure 2. Quantitative calcium measurements with Tq-Ca-FLITS in primary endothelial cells and human organoids. A) Calcium levels in ECs with plasma membrane targeted Tq-Ca-FLITS before and after stimulation with $1 \mu \mathrm{M}$ histamine, indicated by an arrow. The color scale indicates the concentration of calcium and the fluorescence intensity. Scale bar is $40 \mu \mathrm{m}$. B) Time trace of the regions indicated in panel A. C-E) Calcium concentration in ECs during TEM. The ECs express plasma membrane targeted Tq-Ca-FLITS and the leukocytes are labeled with Calcein Red-Orange. C) Fluorescence image of the ECs with the biosensor. The blue outline indicates the location of a neutrophil that crosses the EC monolayer. Scale bar is $30 \mu \mathrm{m}$. D) Top panel, calcium concentration in ECs measured at the location of the neutrophil indicated in panel $\mathrm{C}$ and bottom panel, the fluorescence intensity of Tq-Ca-FLITS and the leukocyte at the same location. The intensity of the neutrophil drops right after crossing the EC monolayer, while the intensity of Tq-Ca-FLITS increases. The concentration of calcium in the EC remains constant, as determined from the fluorescence lifetime of Tq-Ca-FLITS. E) Intensity fold change (dF/F $)$ of Tq-Ca-FLITS (top panel) and measured calcium concentration (bottom panel) in ECs before neutrophil contact, during crawling of the neutrophil, during diapedesis and post-diapedesis (16 TEM events, 7 measurements, 4 batches of neutrophils). The boxplot indicates the median, the 95\% CI (notches), the first and third quartiles (hinges) and the 1.5x Interquartile Range (whiskers) All data points are also indicated by circles. F-G) Calcium changes measured in cells of a human small intestinal organoid stimulated with $10 \mu \mathrm{g} / \mathrm{ml}$ GPBAR-A. F) A human small intestinal organoid expressing Tq-Ca-FLITS in the nuclei of the cells. Scale bar is $30 \mu \mathrm{m}$. G) Heatmap of time traces of the calcium concentration of the cells depicted in panel F, without (left panel) and with (right panel) stimulation by GPBAR-A, indicated by an arrow. Markers indicate the corresponding cells in panel $\mathrm{F}$. 
We have previously shown that ECs actively prevent local leakage from blood vessels when leukocytes cross the endothelial barrier during transendothelial migration (TEM), by inducing a RhoA-dependent F-actin ring that serves as an elastic strap ${ }^{43}$. Whether calcium is involved in the subsequent pore closure is unknown. Although a role for calcium in TEM has been proposed, only the adhesion phase has been studied in some detail, with varying results ${ }^{44}$. The majority of studies used organic dyes with UV excitation and under non-physiological conditions, i.e. under the absence of flow (Supplementary note 4). We regarded conventional intensity-based GECIs unsuited for quantifying local calcium concentrations due to morphological changes of the cells, leading to substantial intensity changes unrelated to calcium concentrations.

We used a model system for TEM that utilizes flow to mimic physiological conditions, similar to the system we used previously to study RhoA activity ${ }^{43}$, but with improvements: (i) we used FLIM in combination with Tq-Ca-FLITS to measure a quantitative output and (ii) we simultaneously imaged fluorescence of the labeled leukocytes, enabling us to precisely correlate the different phases of TEM to the calcium concentration.

We achieved a temporal resolution of 13.5 seconds, which is sufficient to analyze calcium levels during TEM. Changes in the fluorescence intensity of both the endothelial cells and leukocytes (neutrophils) were observed (Figure 2C-D, Movie S3). The leukocyte intensity is affected by cell shape, as we are using a widefield microscope. High fluorescence intensity corresponds to a ball-like shape when the neutrophils are crawling, and low intensity is observed when the neutrophils spread out after completing diapedesis. The intensity of Tq-Ca-FLITS in the ECs was also affected by cell shape, and changes were observed when leukocytes continued to migrate under the EC monolayer. In contrast to the intensity changes, hardly any or no lifetime changes of the calcium probe were observed before adhesion, during crawling or during and after diapedesis of the leukocyte. This translates to hardly any or no calcium changes during TEM (Figure 2E, Movie S3). We analyzed a total of 16 tracks, capturing 98 crawling events and 19 diapedesis events. Also, the calcium concentration before adhesion $(n=216)$ and postdiapedesis $(n=278)$ was determined. The calcium levels in individual cells in almost all these events did not exceed $80 \mathrm{nM}$. This concentration is comparable to calcium concentrations reported in resting EC monolayers earlier ${ }^{44-46}$. In contrast, in the same events we did observe an intensity fold-change post-diapedesis (Figure 2E). The addition 
of ionomycin or histamine to the samples after the TEM assay showed a strong increase in intensity, lifetime and calcium concentration $(>1.5 \mu \mathrm{M})$, demonstrating that the calcium probe was fully functional in the experimental context (Figure S14). Our experimental approach that quantifies the calcium concentration in endothelial cells at different stages of TEM shows that calcium elevation $(>0.08 \mu \mathrm{M})$ in ECs is not essential for pore closure. Next to this, our data suggests that efficient crawling of neutrophils does not require an increase in baseline calcium levels.
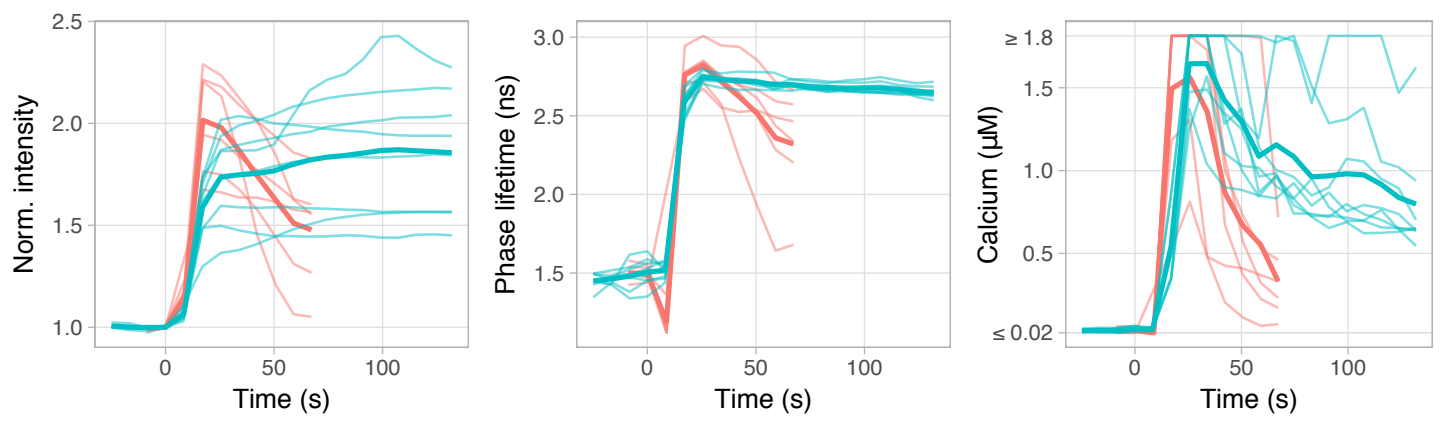

Figure S14. ECs expressing Tq-Ca-FLITS respond to histamine or ionomycin after the TEM assay. The change in intensity (left panel), change in lifetime (middle panel) and corresponding calcium concentration (right panel) are shown for individual cells with thin lines. Thick lines represent the mean. Tq-Ca-FLITS is fully functional in all measured cells (histamine $n=6$, ionomycin $n=8$ ).

Finally, the probe was used to quantify the calcium concentration in a human small intestinal organoid ${ }^{47}$. A nuclear-targeted Tq-Ca-FLITS variant was used to simplify the identification of individual cells. We previously observed an intensity change of the TqCa-FLITS probe in response to stimulation of organoids with an odorant, however lifetime imaging was not performed in that study ${ }^{47}$. Here we investigated whether lifetime changes can be observed in this complex multicellular system. We differentiated organoids to the hormone-producing enteroendocrine cells (EECs), which express multiple G-Protein Coupled Receptors (GPCRs) that control secretion of their products ${ }^{47}$. In vivo, these cells represent less than $1 \%$ of the epithelium, but these can be enriched up to more than $50 \%$ in organoids. Calcium elevation is generally coupled to release of hormones from these cells. Lifetime imaging of the Tq-Ca-FLITS probe in nuclei of organoid cells revealed an intensity increase and a concomitant calcium increase in several cells when GPBAR-A was added. This drug is an agonist for GPBAR1, a GPCR that is expressed mainly by GLP-1-producing L-cells, a subtype of EECs, present in the organoid (Figure 2F-G, Movie S4). We observed a calcium increase by addition of GPBAR-A from 40-80 nM to an elevated baseline of 70-130 nM with occasional spikes up 
bioRxiv preprint doi: https:/doi.org/10.1101/2021.06.21.449214 this version posted June 21,2021 . The copyright holder for this preprint (which was not certified by peer review) is the author/funder, who has granted bioRxiv a license to display the preprint in perpetuity. It is made available under aCC-BY-NC-ND 4.0 International license.

till $250 \mathrm{nM}$. As a control we saturated the calcium sensor in the organoid by addition of Triton-X100 and calcium to the medium (Figure S15).

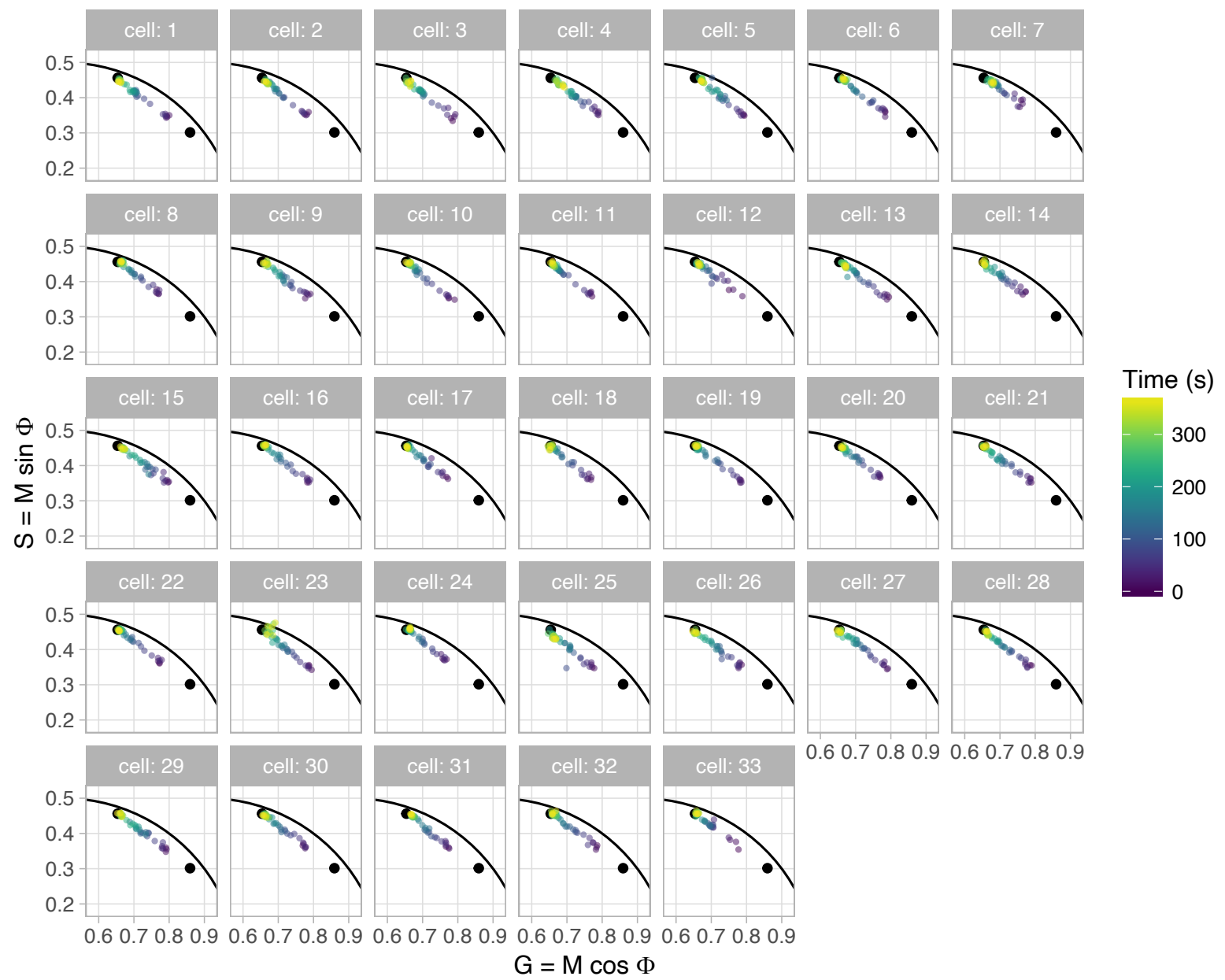

Figure S15. Tq-Ca-FLITS in human small intestinal organoid reacts to addition of $0.25 \%(\mathrm{w} / \mathrm{v})$ Triton-X100 and $12.5 \mathrm{mM}$ calcium. A polar plot representation of the change in lifetime of individual cells $(\mathrm{n}=33)$ is given by the colored dots. The black dots indicate the positions of the calcium bound (upper left) and calcium free (lower right) states of the sensor. ' $M$ ' and ' $\Phi$ ' relate to the modulation and phase lifetime, respectively. At the start of the measurement all cells show a lifetime near the calcium free state and towards the end of the measurement move completely (with a few exceptions) to the lifetime of the calcium bound state.

In summary, we have engineered a genetically encoded sensor for the quantitative detection of calcium. Our results demonstrate that a circular permutated variant of mTurquoise is a viable template for engineering sensors that (i) show lifetime contrast and (ii) are not sensitive to changes in the cytoplasmic $\mathrm{pH}$ range. The use of fluorescence lifetime to quantify calcium concentrations makes the measurements largely insensitive to changes in intensity. This simplifies the calibration in cells and results in a robust in vivo calibration. The lower calcium sensitivity of Tq-Ca-FLITS in vivo compared to in vitro is most likely caused by environmental differences. This demonstrates the need of an in vivo calibration when attempting quantification of intracellular concentrations. Unlike other GECIs, the Tq-Ca-FLITS is not optimized for intensity contrast and is therefore not 
the probe of choice for binary detection of calcium events. Instead, we have optimized this GECI for lifetime contrast, allowing simple, robust and precise quantification of intracellular calcium concentrations. We demonstrate accurate calcium imaging even when intensity fluctuations are caused by morphological changes, as observed during TEM. The temporal resolution was sufficient to capture the transmigration of neutrophil, however it could be greatly improved by choice of microscope. Our setup is not suitable for fast switching of the filters required for alternating imaging of cyan lifetime and red fluorescence, and it suffers from substantial response and dead times. When imaging only the lifetime in the CFP channel we reached a temporal resolution with Tq-Ca-FLITS of 3 seconds. Lifetime imaging can be further decreased to sub-second resolution by choice of improved and faster lifetime microscopy techniques such as a FALCON or Stellaris systems $^{48}$ or siFLIM $^{49}$. The relative intrinsic brightness of Tq-Ca-FLITS is $25-75 \%$ ('off'and 'on'-state respectively) of mTurquoise2, the brightest cyan FP available. Moreover, in the 'off'-state the intrinsic brightness of the Tq-Ca-FLITS is $\sim 76 \%$ of ECFP50, which is still commonly used in FRET ratio probes for timelapse imaging. Therefore, we expect that TqCa-FLITS is suitable for faster and dynamic imaging of calcium concentrations than is demonstrated here.

The experiments with organoids show that we can accurately measure calcium levels in a complex 3D tissue. Human organoids are widely used for modeling of epithelial physiology. Previous work has highlighted - based on single cell transcriptomic analysis - the near-identical nature of organoid cells compared to their tissue counterparts ${ }^{51}$. The cellular heterogeneity of organoids may well facilitate quantifying cell type-specific calcium responses in a physiologically relevant context. We chose to assess calcium dynamics in human EECs, which eventually control hormone secretion. Human EECs differ greatly from their murine counterparts in terms of their expression profile of GPCRs, and therefore organoids represent a unique model to study EEC functioning in man. These endocrine cells represent important potential targets for treatments of metabolic diseases, as their hormones are involved in controlling key physiological processes such as appetite and insulin secretion. To increase the accuracy of measurements in thick samples, optical sectioning is necessary. This can be achieved by combing lifetime imaging with confocal scanning, light sheet imaging or multiphoton excitation.

To conclude, Tq-Ca-FLITS is the first GECI that incorporates a novel sensing mechanism based on a conformational change that directly modifies only the fluorescence quantum 
bioRxiv preprint doi: https://doi.org/10.1101/2021.06.21.449214; this version posted June 21, 2021. The copyright holder for this preprint (which was not certified by peer review) is the author/funder, who has granted bioRxiv a license to display the preprint in perpetuity. It is made available under aCC-BY-NC-ND 4.0 International license.

yield and fluorescence lifetime of a fluorescent protein independent of FRET (and without the need for a second fluorescent protein), providing contrast independent of sensor concentration. We anticipate that this novel sensor design can be easily combined with other sensor domains, e.g. reporting on phosphorylation and small molecule- or proteinbinding, to generate an entire new class of fluorescence biosensors for the quantitative analysis of cellular processes. 
bioRxiv preprint doi: https://doi.org/10.1101/2021.06.21.449214; this version posted June 21 , 2021. The copyright holder for this preprint (which was not certified by peer review) is the author/funder, who has granted bioRxiv a license to display the preprint in perpetuity. It is made available under aCC-BY-NC-ND 4.0 International license.

\section{Methods}

General Cloning. We used Escherichia coli strain E. cloni 5-alpha (short: E. cloni, Lucigen corporation) for all cloning procedures. For DNA assembly, competent E. cloni was transformed using a heat shock protocol according to manufacturers' instructions. For protein expression, $E$. cloni was grown using super optimal broth (SOB, $0.5 \%$ (w/v) yeast extract, $2 \%\left(\mathrm{w} / \mathrm{v}\right.$ ) tryptone, $10 \mathrm{mM} \mathrm{NaCl}, 20 \mathrm{mM} \mathrm{MgSO}_{4}$, $2.5 \mathrm{mM} \mathrm{KCl}$ ) supplemented with $100 \mu \mathrm{g} / \mathrm{ml}$ kanamycin and $0.2 \%(\mathrm{w} / \mathrm{v})$ rhamnose. $1.5 \%(\mathrm{w} / \mathrm{v})$ agar was added for agar plates. Bacteria were grown overnight at $37^{\circ} \mathrm{C}$. Plasmid DNA was extracted from bacteria using the GeneJET Plasmid Miniprep Kit (Thermo Fisher Scientific) and the obtained concentration was determined by Nanodrop (Life Technologies).

DNA fragments were generated by Polymerase Chain Reaction (PCR), using Pfu DNA polymerase (Agilent Technologies) unless otherwise indicated. DNA fragments were visualized by gel electrophoresis on a 1\% agarose gel, run for $30 \mathrm{~min}$ at $80 \mathrm{~V}$. PCR fragments were purified using the GeneJET PCR purification Kit (Thermo Fisher Scientific) and digested with restriction enzymes to generate sticky ends. Restriction enzymes were heat inactivated at $80{ }^{\circ} \mathrm{C}$ for $20 \mathrm{~min}$ if necessary. Vector fragments were generated by restriction of plasmids and the correct bands were extracted from gel using the GeneJET Gel Extraction Kit (Thermo Fisher Scientific).

DNA fragments were ligated using T4 DNA ligase (Thermo Fisher Scientific), per the manufacturers' protocol. Correct construction of plasmids was verified by control digestion and sequencing (primers 38-39, Macrogen Europe). All primers (Table S5) were ordered from Integrated DNA Technologies.

Generating the dual expression vector. The pFHL-plasmid for dual expression was constructed using four DNA fragments: (i) the Kanamycin resistance gene and ColE1 origen of replication from a C1 plasmid (Addgene plasmid \#54842), followed by (ii) the dual promoter region from a pDuEx plasmid (pDress were the mTurquoise2, large spatial linker and P2A sequences were removed from the plasmid using NheI restriction sites ${ }^{35}$ ), (iii) the sequence coding for R-GECO1 including TorA-tag from pTorPE-R-GECO1 (a gift from Robert Campbell (Addgene plasmid \#32465; http://n2t.net/addgene:32465; RRID:Addgene_32465), and (iv) the terminator region from a pDuEx plasmid. The four DNA fragments were generated by PCR amplification with Phusion High-Fidelity DNA Polymerase (Thermo Fisher Scientific) (primers 1-8). The DNA fragments were assembled using Gibson assembly52. E. cloni was transformed with the Gibson mix and correct construction was verified by digestion analysis and sequencing of the plasmid.

Engineering of Tq-Ca-FLITS. Circular permutated mTurquoise2 (cpTq2) variants were constructed by PCR amplification from a tandem construct containing two mTurquoise 2 proteins connected by a flexible GGSGG-linker (primers 9-26). mApple in R-GECO1 on pFHL-R-GEC01 was replaced with different cpTq2 variants by digestion of the vector and PCR fragments with SacI and MluI, followed by ligation. To create a library of sensors with different linker lengths, a similar approach was taken, but now a library of cpTq2 fragments was generated by PCR using a mix of primers (primers 14-21 and 27). To create mutations at positions 146 and 150 of the fluorescent protein (mTq2 numbering), again the same approach was taken, now using primers containing altered or degenerated codons (primers 28-32).

Mutations were also made at position 150 of regular mTurquoise2, by PCR amplification with primers containing a degenerated codon (primers 33-34). The PCR mix was DpnI digested and used for transformation. 
Table S5. Primers for construction of Tq-Ca-FLITS

\begin{tabular}{ll}
\hline \multicolumn{1}{c}{ No. Sequence } & Use \\
\hline 1 TCGGGGAAATGTGCGCGG & C1 plasmid as template \\
2 TCAGGGGATAACGCAGGAAAG & C1 plasmid as template \\
3 tcacatgttctttcctgcgttatccctgate is indicated. \\
4 cctctttaaacccatGGTATATCTCCTTCTTATAGTTAAACAAAATTAT & pDuEx plasmid as template \\
TTC & pDex plasmid as template \\
6 cctgaggttaatcacAAGCTTCTACTTCGCTGTC & TorPE-R-GEC01 as template \\
7 gcgaagtagaagcttGTGATTAACCTCAGGTGCAG & TorPE-R-GECO1 as template \\
8 caaataggggttccgcgcacatttccccgaGCATGCTTTCAGCAAAAAAC & pDuEx plasmid as template \\
\hline
\end{tabular}

Sensors with variation in insertion site

9 gctgagctcacccgtggttTTTAGCGACAACGTCTATATC

10 gtcacgcgtGTAGTTGTACTCCAGCTTG

FW cp146 sensor

11 gctgagctcacccgtggttAGCGACAACGTCTATATC

RV cp146 sensor

12 gtcacgcgtAAAGTAGTTGTACTCCAGC

FW cp147 sensor

13 gctgagctcacccgtggttGACAACGTCTATATCACCG

RV cp147 sensor

14 gtcacgcgtGCTAAAGTAGTTGTACTCC

FW cp148 sensor

15 gctgagctcacccgtggttAACGTCTATATCACCGCC

RV cp148 sensor

16 gtcacgcgtGTCGCTAAAGTAGTTGTAC

FW cp149 sensor

17 gctgagctcacccgtggttGTCTATATCACCGCCGAC

RV cp149 sensor

18 gtcacgcgtGTTGTCGCTAAAGTAGTTG

FW cp150 sensor

19 gctgagctcacccgtggttTATATCACCGCCGACAAGC

RV cp150 sensor

20 gtcacgcgtGACGTTGTCGCTAAAGTAG

FW cp151 sensor

21 gctgagctcacccgtggttATCACCGCCGACAAGCAG

RV cp151 sensor

22 gtcacgcgtATAGACGTTGTCGCTAAAG

FW cp152 sensor

23 gctgagctcacccgtggttACCCAGTCCAAGCTGAGC

RV cp152 sensor

24 gtcacgcgtGCTCAGGTAGTGGTTGTC

FW cp203 sensor

25 gctgagctcacccgtggttCAGTCCAAGCTGAGCAAAG

RV cp203 sensor

26 gtcacgcgtGGTGCTCAGGTAGTGGTTG

FW cp204 sensor

27 gtcacgcgtGTTGTACTCCAGCTTGTGC

RV cp204 sensor

RV cp145 sensor

\begin{tabular}{|c|c|}
\hline \multicolumn{2}{|l|}{ Mutations } \\
\hline 28 gctgagctcacccgtggttNNKTATATCACCGCCGACAAG & V150X on Tq-Ca-FLITS.0 \\
\hline 29 gtcacgcgtGTTGTCGCTMNNGTAGTTGTACTCCAGC & F146X on Tq-Ca-FLITS.0 \\
\hline 30 gctgagctcacccgtggttGCGTATATCACCGCCGACAAG & V150A on Tq-Ca-FLITS.0 \\
\hline 31 gctgagctcacccgtggttMTCTATATCACCGCCGACAAG & V150I/L on Tq-Ca-FLITS. 0 \\
\hline 32 gtcacgcgtGTTGTCGCTATAGTAGTTG & F146Y on Tq-Ca-FLITS.0 \\
\hline 33 CTACTTTAGCGACAACNNKTATATCACCGCCGAC & V150X on mTurquoise2 \\
\hline 34 GTCGGCGGTGATATAMNNGTTGTCGCTAAAGTAG & V150X on mTurquoise2 \\
\hline \multicolumn{2}{|l|}{ Organelle targeting } \\
\hline 35 gctaccggtcgccaccATGGTCGACTCTTCACG & FW, all variants \\
\hline 36 ttttgtacacCTTCGCTGTCATCATTTGGACAAACTC & RV, Golgi and membrane \\
\hline 37 ttttgtacacCTACTTCGCTGTCATCATTTGGACAAACTC & $\begin{array}{l}\text { RV, including STOP codon, } \\
\text { nuclear and cytoplasmic }\end{array}$ \\
\hline \multicolumn{2}{|l|}{ Sequencing } \\
\hline 38 GTGGACAGCAAATGGGTCG & FW, sensor variants \\
\hline 39 CCCAGAGACCGCATCACC & $\mathrm{RV}$, sensor variants \\
\hline
\end{tabular}

Annealing regions are indicated by capital letters, mutations in bold. 
Plasmids for expression in mammalian cells. The sensor sequence was amplified by PCR (primers 35-37) to generate cytoplasmic, nuclear, membrane and Golgi targeted versions of Tq-Ca-FLITS for transient transfection of mammalian cells. DNA fragments and vectors carrying the desired tag were digested with AgeI and BsrGI, followed by ligation. Of the following vectors the fluorescent protein was exchanged for Tq-Ca-FLITS: 3xnls-mTurquoise2 (Addgene plasmid \#98817) for a nuclear tag, pLck-mVenus-C1 (Addgene plasmid \#84337) for a membrane tag, pmScarlet_Giantin_C1 (Addgene plasmid \#85048) for a Golgi tag and mVenus-N1 (color variant of Addgene plasmid \#54843) for an untagged version.

To generate stable cell lines, we used either the piggyBac transposase system or lentiviral transduction. To this end, Tq-Ca-FLITS including the $3 \times$ nnls sequence was cloned into a PiggyBac vector containing a Puromycin resistance gene, by digestion with EcoRI/NotI and ligation, yielding pPB-3xnls-Tq-Ca-FLITS. The lentiviral plasmid for the doxycyclin-inducible expression of Tq-Ca-FLITS in organoids was adapted from the previously described pInducer20 x NLS-mKate2P2A-HRAS ${ }^{\mathrm{N} 17} 53$. The following replacements were made via In-Fusion HD cloning kit (Clontech Laboratories) : NLS-mKate2 reporter fluorophore was replaced by PCR encoding NLS-mMaroon (primers FW 5'-3' actagtccagACGCGtCcaccATGCcaaagaagaaacggaaggtaggatcaatggtgagcaagggcgag, RV 5'-3' ttgtacagctccGTTAACccattaagtttgtgccccagtttgc); HRAS ${ }^{\mathrm{N} 17}$ was replaced by PCR encoding Tq-Ca-FLITS (primers FW 5'-3' CCCTGGACCTGCTAGCatgggatcagatccaaaaaagaagagaaa, RV 5'-3' gccctctagactcgagCTACTTCGCTGTCATCATTTGGACAAAC); ires-puro resistance cassette was replaced by ires-blast (primers FW 5'-3' taaggatccgcggccGCATCGATGCCTAGTGCCATTTGTTCAGTG, RV 5'-3' tctagagtcgcggccgcCATGCATTTAGCCCTCCCACAC). The resulting plasmid is indicated as pInducer-NLS-mMaroon-P2A-3xnls-Tq-Ca-FLITS.

We also constructed a plasmid for lentiviral transduction for normal expression of Tq-Ca-FLITS. Here In-Fusion Cloning was used to insert the coding sequences of H2B-mMaroon and 3xnls-Tq-Ca-FLITS connected with a P2A sequence in a lentiviral vector. The resulting plasmid is indicated as pLV-H2B-Maroon-P2A3xnls-Tq-Ca-FLITS.

Bacterial screening. E. cloni bacteria were used for two screening methods.

(i) Bacterial test. Bacteria expressing a sensor variant with the TorA-tag were grown overnight $(\mathrm{O} / \mathrm{N})$ in Luria-Bertani medium (LB, $10 \mathrm{~g} / \mathrm{L}$ Bacto Tryptone, 5 $\mathrm{g} / \mathrm{L}$ Bacto Yeast extract, $10 \mathrm{~g} / \mathrm{L} \mathrm{NaCl}$ ). The bacterial suspension was pipetted in triplicate in a CELLSTAR 96-wells plate with black walls (655090, Greiner-Bio). Intensity was recorded at room temperature (RT) using a FL600 microplate fluorescence reader controlled by $\mathrm{KC}^{\mathrm{TM}}$ software (Bio-Tek) with 430/25, 485/20 or $555 / 25 \mathrm{~nm}$ excitation and $485 / 40,530 / 25$ or $620 / 40 \mathrm{~nm}$ emission for respectively CFP, GFP or RFP, and averaging each well 10x. Intensity was again recorded after addition of $0.5 \mathrm{mM}$ EDTA or MilliQ water (control). Intensities were divided by a well with $0.05 \mathrm{mg} / \mathrm{ml}$ Erythrosin B (EB), and a background (clear LB) was subtracted. Finally, wells were normalized to the first read of the same well to obtain the intensity fold-change $F_{\max } / F_{0}$.

(ii) Periplasm test. Alternatively, the periplasmic shock fluid containing the sensor was isolated, using a cold osmotic shock protocol as described before ${ }^{6}$. Intensity 
of periplasmic fluid was measured before and after addition of $0.1 \mathrm{mM} \mathrm{CaCl}_{2}$ or MilliQ water, using the microplate reader described above. Intensities were divided by a well with $0.05 \mathrm{mg} / \mathrm{ml} \mathrm{EB}$, background (clear buffer) was subtracted and wells were normalized to the first read of the same well to obtain the intensity fold-change $F_{\max } / F_{0}$. Each periplasmic isolate was measured in duplicate.

HeLa cell culture. HeLa cells acquired from the American Tissue Culture Collection were maintained in full medium, DMEM + GlutaMAX (61965, Gibco) supplemented with $10 \%$ FBS (10270, Gibco), under $7 \%$ humidified $\mathrm{CO}_{2}$ atmosphere at $37^{\circ} \mathrm{C}$. Cells were washed with HBSS (14175, Gibco) and trypsinized (25300, Gibco) for passaging. No antibiotics were used unless otherwise stated.

HeLa cells were grown on round cover slips (Menzel, no. 1, $24 \mathrm{~mm}$ diameter, Thermo Fisher Scientific) in a 6-wells plate for imaging. Transfection mixture was prepared in Opti-MEM (31985047, Thermo Fisher Scientific) with $2.25 \mu \mathrm{g}$ Polyethylenimine in water (PEI, pH 7.3, 23966, Polysciences) and 250 ng plasmid DNA, and incubated for 20 min before addition to the cells. The coverslips were 1or 2-days post-transfection mounted in an AttoFluor cell chamber (A7816, Thermo Fisher Scientific) and microscopy medium (137 mM NaCl, $5.4 \mathrm{mM} \mathrm{KCl}, 1.8$ $\mathrm{mM} \mathrm{CaCl}_{2}, 0.8 \mathrm{mM} \mathrm{MgSO}_{4}, 20 \mathrm{mM}$ D-Glucose, $20 \mathrm{mM}$ HEPES pH 7.4) was added.

Stable expression of Tq-Ca-FLITS in HeLa. HeLa cells were transfected with pPB-3xnls-Tq-Ca-FLITS using PEI as transfection agent. One day post-transfection, transfected cells were selected by addition of puromycin $(1 \mu \mathrm{g} / \mathrm{ml})$ to the medium for 24h. The remaining cells were expanded for Fluorescence Assisted Cell Sorting (FACS). Briefly, cells were washed, trypsinized, resuspended in full medium and spun down at $1000 \mathrm{rpm}$ for $4 \mathrm{~min}$. Cells were washed twice in HF (2\% FBS in HBSS) and resuspended in an appropriate volume of HF. The cell suspension was filtered through a $70 \mu \mathrm{m}$ filter. Cells were sorted into full medium supplemented with P/S (100 U/ml penicillin and $100 \mu \mathrm{g} / \mathrm{ml}$ streptomycin) and $25 \mathrm{mM} \mathrm{HEPES}$ (pH 7.4) on a BD FACSARIA3, with $407 \mathrm{~nm}$ excitation and $502 \mathrm{~nm}$ long-pass and $510 / 50 \mathrm{~nm}$ band-pass emission filters. The sample chamber and collection devices were set at $4{ }^{\circ} \mathrm{C}$ for increased cell survival.

Single cells were gated based on Forward and Side Scatter (FSC/SSC). Live cell gating with DAPI was not possible due to spectral overlap with the fluorescence of Tq-Ca-FLITS. The positive gate for Tq-Ca-FLITS was determined based on untransfected wild-type HeLa cells. Cells were sorted into a high (34\% of positive events) and low (66\%) fluorescent pool. FACS data were analyzed with FlowJo. After sorting, cells were cultured with $\mathrm{P} / \mathrm{S}$ for several weeks or until freezing down. Cells from the high pool were used for in vivo calibration of Tq-Ca-FLITS.

Lifetime imaging. Fluorescence lifetime was recorded at RT with a 15-20 s interval, before and after addition of a mix of ionomycin $(10 \mu \mathrm{g} / \mathrm{ml}, \mathrm{I}-6800$, LClaboratories) and calcium (5 mM). Two frequency domain FLIM microscopes were used.

(i) A home-build Zeiss setup controlled by Matlab 6.1 software, composed of an Axiovert 200M inverted fluorescence microscope (Zeiss) with a II18MD modulated image intensifier (Lambert Instruments) coupled to a CoolSNAP HQ CCD camera (Roper Scientific) and two computer-controlled HF-frequency synthesizers (SML 01, Rohde \& Schwartz), one driving the intensifier and the 
other driving a $440 \mathrm{~nm}$ modulated laser diode (PicoQuant, LDH-M-C-440) through an MDL-300 driver unit ${ }^{54}$. The excitation light is modulated at $75.1 \mathrm{MHz}$ and reflected by a $455 \mathrm{~nm}$ dichroic mirror onto the sample. Emission is filtered with a $480 / 40 \mathrm{~nm}$ band-pass emission filter. A 40X (Plan NeoFluar NA 1.3 oil) objective was used.

(ii) A LIFA setup composed of an Eclipse Ti microscope (Nikon) with a Lambert Instruments Multi-LED for excitation, a $\mathrm{LI}^{2} \mathrm{CAM}$ camera and a LIFA signal generator (all Lambert Instruments) to synchronize the light source and the camera. For CFP excitation a $446 \mathrm{~nm}$ LED was used, combined with a 448/20 nm excitation filter, a $442 \mathrm{~nm}$ dichroic mirror and a $482 / 25 \mathrm{~nm}$ band-pass filter. For RFP excitation a $532 \mathrm{~nm}$ LED was used, combined with a 534/20 nm excitation filter, a $561 \mathrm{~nm}$ dichroic mirror and a 609/54 nm band-pass filter (all filters from Semrock). Alexa488 or EB was used as a reference to calibrate the instrumentation, with a known mono-exponential lifetime of 4.05 ns $^{18,55,56}$ or 0.086 ns $^{57-59}$ respectively. Cells were imaged using a 40x (Plan Apo, NA 0.95 air) or a $60 x$ (Plan Apo, NA 1.40 oil) objective.

Data from the Zeiss setup was analyzed as described before ${ }^{60}$. Data from the LIFA setup was converted to lifetime images by the LI-FLIM software (version 1.2.13). Regions of interest (ROIs) were selected to extract the average lifetime. Only cells with appropriate average intensity were selected to avoid influence of background fluorescence ( $>200$ for the Zeiss setup, $>2000$ for the LIFA setup). The in vivo foldchange $F_{\max } / F_{0}$ of Tq-Ca-FLITS was determined from the intensity data of a FLIM stack, corrected for background intensity.

Ratiometric imaging. Fluorescent ratio imaging was with two different microscopes at $37^{\circ} \mathrm{C}$. (i) An Eclipse Ti microscope (Nikon) equipped with an Intensilight C-HGFIE (Nikon) for excitation and an Orca-Flash4.0 camera (Hamamatsu). Cells were imaged using a 40x (Plan Apo, NA 0.95 air) objective. For FRET imaging of YCaM3.60 we used a 448/20 nm excitation filter combined with a $4 \underline{42} \mathrm{~nm}$ dichroic mirror and a $482 / 25 \mathrm{~nm}$ emission filter for the donor, and a 514 $\mathrm{nm}$ dichroic mirror and a 542/27 nm emission filter for the acceptor. For MatryoshCaMP6s we used a 448/20 nm excitation filter, a $\underline{488} \mathrm{~nm}$ dichroic mirror and a 520/30 nm emission filter for imaging of the GFP and a 448/20 nm excitation filter, a $561 \mathrm{~nm}$ dichroic mirror and a 609/54 nm emission filter for LSSmOrange (all filters from Semrock).

(ii) An Axiovert 200M inverted fluorescence microscope (ZEISS) equipped with an Intensilight C-HGFIE (Nikon) for excitation and a CoolSNAP HQ CCD camera (Roper Scientific). Cells were imaged using a 40x (Plan Neofluar, NA 1.30 oil) objective. YCaM3.60 was excited with $420 / 30 \mathrm{~nm}$. A $455 \mathrm{~nm}$ dichroic mirror was used. CFP fluorescence was collected at $470 / 30 \mathrm{~nm}$ and YFP fluorescence at $535 / 30 \mathrm{~nm}$. MatryoshCaMP6s was excited with $440 / 30 \mathrm{~nm}$ followed by a $490 \mathrm{~nm}$ dichroic mirror. GFP fluorescence was collected at 525/40 nm and LSSmOrange fluorescence at $600 / 37 \mathrm{~nm}$.

Background intensity was subtracted from the images and a ratio image was calculated using ImageJ (version 1.52k). The average intensity of each channel and the ratio was determined for individual cells.

Protein isolation. His-tagged Tq-Ca-FLITS, jGCaMP7c, RCaMP1h and mTurquoise 2 were isolated from bacterial culture essentially as described before, 
using $\mathrm{Ni}^{2+}$ loaded His-Bind resin'61. In the final step, the isolated protein was overnight dialyzed in $10 \mathrm{mM}$ Tris- $\mathrm{HCl} \mathrm{pH}$ 8.0. No further purification was performed.

Quantum yield. Purified Tq-Ca-FLITS and jGCaMP7c were diluted 10x in $10 \mathrm{mM}$ Tris $\mathrm{HCl}$ with $100 \mu \mathrm{M} \mathrm{CaCl}_{2}$ or $5 \mathrm{mM} \mathrm{EGTA}$, for the calcium bound or unbound state respectively. The absorbance spectra were measured with a spectrophotometer (Libra S70, Biochrom) between 260-650 $\mathrm{nm}$ for CFP and 260-700 $\mathrm{nm}$ for GFP (step size $1 \mathrm{~nm}$, bandwidth $2 \mathrm{~nm}$ ). Buffer without protein was used as reference. Each dilution was measured three times. Three dilutions were made using the initial dilution, with an absorbance at $440 \mathrm{~nm}\left(A_{440}\right)$ of $0.002<A_{440}<0.02$, each in triplicate. Emission and excitation spectra were recorded with a LS55 fluorimeter controlled by FL WinLab software (Perkin Elmer), with a step size of $0.5 \mathrm{~nm}$ and a scan speed of $200 \mathrm{~nm} / \mathrm{min}$ and using buffer as reference. Emission was recorded at $450-650 \mathrm{~nm}(2.5 \mathrm{~nm}$ slit) with $440 \mathrm{~nm}$ excitation ( $4 \mathrm{~nm}$ slit). Excitation spectra were recorded at $250-490$ or $250-530 \mathrm{~nm}$ ( $2.5 \mathrm{~nm}$ slit) measuring emission at 500 or 540 ( $4 \mathrm{~nm}$ slit), for CFP and GFP respectively.

Absorbance spectra were corrected by subtraction of the offset of the spectrum between 631-650 nm. Emission spectra were corrected for spectral sensitivity of the detector. The spectral area $\left(I_{e m}\right)$ under corrected emission spectra was calculated by integration between $450-650 \mathrm{~nm}$. The $A_{440}$ was plotted versus the 'I $I_{e m}$ ' and the slope ' $s$ ' was determined while forcing the regression line through the origin, $A_{440}=s \times I_{e m}$. The Quantum Yield $(Q Y)$ was determined using mTurquoise2 as reference with a know $Q Y$ of 0.93 (Equation 1).

$Q Y_{s}=Q Y_{r} \times \frac{s_{s}}{s_{r}}$

Subscripts ' $s$ ' and ' $r$ ' indicate the sample and the reference respectively. The average emission and excitation spectra were calculated from the highest protein concentration.

Extinction coefficient. Purified Tq-Ca-FLITS was 4x diluted in calcium buffers containing 0 or $39 \mu \mathrm{M}$ free calcium of the Calcium Calibration Buffer Kit \#1 (C3008MP, Thermo Fisher Scientific). The absorbance spectra were measured before and $>5 \mathrm{~min}$ after addition of $1 \mathrm{M} \mathrm{NaOH}$, at 260-650 $\mathrm{nm}$ with $1 \mathrm{~nm}$ step size and $1 \mathrm{~nm}$ bandwidth. Corresponding buffer was used as reference. The concentration of unfolded protein was determined using the Beer-Lambert law and assuming an extinction coefficient $(\varepsilon)$ at $462 \mathrm{~nm}$ of $46 \mathrm{mM}^{-1} \mathrm{~cm}^{-1}$ for the free cyan chromophore ${ }^{62}$. Next, $\varepsilon$ was determined at $440 \mathrm{~nm}$ for the calcium free and bound states. The average absorbance spectra of three measurements were plotted.

In vitro calibration. Purified Tq-Ca-FLITS and jGCaMP7c were diluted $100 \mathrm{x}$ in calcium buffers ranging from 0 to $39 \mu \mathrm{M}$, using the Calcium Calibration Buffer Kit \#1 according to manufacturers' instructions. Dilutions were made in triplicate. Fluorescence was measured at RT in a 96-wells-plate with black walls and flat glass bottom (89626, Ibidi) using a microplate fluorescence reader with settings as described under Bacterial screening. The fluorescence ' $f$ ' was fit to the Hill equation to determine the $K_{d}$, using the Nonlinear Least Squares method of the $\mathrm{R}$ 
Stats Package (version 3.3.3) in R Studio (version 1.0.136) with default settings (Equation 2).

$f=f_{\min }+\frac{\left(f_{\max }-f_{\min }\right)}{\left(\frac{K_{d}}{L}\right)^{n}+1}$

Subscripts ' $m a x$ ' and ' $m i n$ ' indicate the maximum and minimum fluorescence, ' $K_{d}$ ' the microscopic dissociation constant, ' $L$ ' the known free $\mathrm{Ca}^{2+}$ concentration and ' $n$ ' the Hill-coefficient.

The lifetime of each well in the same 96-wells plate was recorded at RT using the LIFA setup described earlier, using the 40x (Plan Apo, NA 0.95 air) objective. Recorded sample stacks and a reference stack were converted into lifetime images by an Image macro $^{35,63}$.

The average phase and modulation lifetime $\left(\tau_{\varphi}\right.$ and $\left.\tau_{M}\right)$ of the full view were extracted. Both lifetimes were separately fitted with the Hill equation (Equation 2), with ' $\tau$ ' instead of ' $f$ ', using the Nonlinear Least Squares method of the R Stats Package (version 3.3.3) in R Studio (version 1.0.136) with default settings. The Phase $(\Phi)$ and modulation $(M)$ were calculated from the recorded lifetimes and displayed in a polar plot as $G$ and $S$ coordinates (Equations 3).

$$
\begin{array}{lll}
\Phi=\operatorname{atan}\left(\omega \tau_{\varphi}\right) & \text { and } & M=\sqrt{\frac{1}{1+\left(\omega \tau_{M}\right)^{2}}} \\
G=M \cos (\Phi) & \text { and } & S=M \sin (\Phi)
\end{array}
$$

The angular frequency of modulation, $2 \pi f$, is given by ' $\omega$ '. Measurements were projected on the straight line between the two extremes (min and max) and converted to line fraction ' $a$ ' (Equations 4).

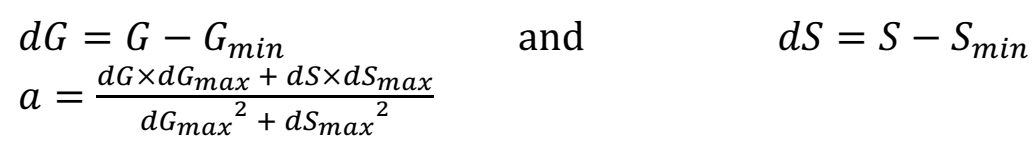

The line fraction was corrected of for the intensity contribution of the two states to find the true fraction ' $F$ ', with $F=1$ representing all sensors in the calcium bound state (Equation 5). The intensity ratio $(R)$ between states in vitro was determined to be $R=3.51$ at $\mathrm{pH} 7.0$, based on $f_{\max } / f_{\min }$ from the $\mathbf{p H}$ sensitivity experiments.

$F=\frac{a}{R \times(1-a)+a}$

The fraction $(F)$ was fitted with the Hill equation (Equation 2) with ' $F$ ' instead of ' $f$ ' to find the in vitro $K_{d}$, using the Nonlinear Least Squares method of the R Stats Package (version 3.3.3) in R Studio (version 1.0.136), using the port algorithm.

In vivo calibration. All steps were performed at $37^{\circ} \mathrm{C}$. Calcium buffers ranging from 0 to $39 \mu \mathrm{M}$ (11 concentrations, in triplicate) were prepared using the Calcium Calibration Buffer Kit \#1. HeLa cells stably expressing nuclear targeted Tq-CaFLITS were grown on cover slips and mounted in a cell chamber as described above. Cells were washed twice with HBSS without calcium $(14175$, Gibco) and calcium buffer was added. Cells were incubated for 15-20 min with $4 \mu \mathrm{g} / \mathrm{ml}$ 
rotenone and $1.8 \mathrm{mM}$ 2-deoxy-D-glucose. Lifetime stacks were recorded using the LIFA setup described previously while adding $10 \mu \mathrm{M}$ of digitonin. A 40x (Plan Apo, NA 0.95 air) objective was used and fluorescence lifetime was recorded every 20 s. Recorded data was converted into lifetime images by an ImageJ macro 35,63 . The average lifetimes of all pixels in a view with intensity $>1000$ were plotted over time (approximately 30-50 cells per view). Equilibrium was reached (reaction to digitonin) after $>6 \mathrm{~min}$ and the corresponding lifetimes were listed. Next, the same approach to determine the in vivo $K_{d}$ was taken as for the in vitro data, using $R=3.02$ as determined from $F_{\max } / F_{0}$ from HeLa cells stimulated with ionomycin and calcium.

Additionally, line fraction ' $a$ ' was fitted with the Hill equation (Equation 2), with ' $a$ ' instead of ' $f$ ', to determine parameters for conversion of experimental data to calcium concentrations, without the need to correct for intensity contribution of the calcium free and bound states.

The sample standard deviation of the fraction ' $F$ ' was calculated for the highest and lowest calcium concentration, 0 and $39 \mu \mathrm{M}$. From this we determined the $95 \%$ confidence interval $(C D)$. To determine the lowest fraction we can reliably measure, we added the $95 \% C I$ to the mean of the $0 \mu \mathrm{M}$ calcium measurements. To determine the highest measurable fraction we did a subtraction.

pH sensitivity. A series of buffers ranging from $\mathrm{pH} 2.8$ to 10.0 were prepared, using $50 \mathrm{mM}$ citrate buffer (pH 2.8-5.8), MOPS buffer (pH 6.3-7.9) and glycine/ $\mathrm{NaOH}$ buffer ( $\mathrm{pH} 8.3-10.0)$. Buffers additionally contain $0.1 \mathrm{M} \mathrm{KCl}$ and 0.1 $\mathrm{mM} \mathrm{CaCl}_{2}$ or $5 \mathrm{mM}$ EGTA. The $\mathrm{pH}$ of each buffer was determined including all components shortly before use. Purified Tq-Ca-FLITS, jGCaMP7c or RCaMP1h was diluted 100x in the prepared buffers.

Fluorescence was measured in triplicate in a 96-wells-plate with black walls and flat glass bottom (89626, ibidi) using a FL600 microplate fluorescence reader controlled by $\mathrm{KC}^{\mathrm{TM}}$ software (Bio-Tek) with settings as described under Bacterial screening. The fluorescence intensity (f) was corrected for background and fit to the Henderson-Hasselbalch equation (Equation 6) using the Nonlinear Least Squares method of the $\mathrm{R}$ Stats Package (version 3.3.3) in $\mathrm{R}$ Studio (version 1.0.136), using the port algorithm restricted to $f$ min $\leq 0$. The calcium bound state of Tq-Ca-FLITS did not fit to this model, therefore a model with two $\mathrm{p} K_{a}$ values was applied (Equation 7).

$f=f_{\min }+\frac{\left(f_{\max }-f_{\min }\right)}{1+10^{n\left(p K_{a}-p H\right)}}$

$f=f_{\text {min }}+\frac{\left(f_{\text {med }}-f_{\text {min }}\right)}{1+10^{n_{1}\left(p K_{a, 1}-p H\right)}}+\frac{\left(f_{\text {max }}-f_{\text {med }}\right)}{1+10^{n_{2}\left(p K_{a, 2}-p H\right)}}$

The ' $n$ ' indicates the Hill coefficient, ' $\mathrm{p} K_{a}$ ' the apparent $\mathrm{p} K_{a}$ and ' $m i n$ ', 'med' and ' $m a x^{\prime}$ the minimum, a medium and the maximum fluorescence. The model for the $\mathrm{Ca}^{2+}$ saturated state was divided over the model of the $\mathrm{Ca}^{2+}$ free state to gain the dynamic range.

The lifetime of each well in the same 96-wells plate was recorded at RT similar to the in vitro calibration. Recorded data was converted into lifetime images by the LI-FLIM software (version 1.2.13). The average phase and modulation lifetime $\left(\tau_{\varphi}\right.$ and $\tau_{M}$ ) of the full view were extracted. 
Magnesium sensitivity. A series of buffers was prepared at $\mathrm{pH} 7.1$ and $20{ }^{\circ} \mathrm{C}$, each designed to contain a specific concentration of free magnesium ions $(0,0.9,1.8$, 3.7, 9.3 and $18.7 \mathrm{mM}$ ) and either 0 or $1 \mathrm{mM}$ free calcium, as calculated using the program 'Ca-Mg-ATP-EGTA Calculator v1.0 using constants from NIST database \#46 v8'. The buffers including calcium contain each $1 \mathrm{mM} \mathrm{CaCl}_{2}, 20 \mathrm{mM}$ HEPES pH7.1 and $0,0.9,1.8,3.7,9.3$ or $18.7 \mathrm{mM} \mathrm{MgCl}_{2}$. The calcium free buffers contain each $3 \mathrm{mM}$ EGTA, $20 \mathrm{mM}$ HEPES pH7.1 and 0, 1, 2, 4, 10 or $20 \mathrm{mM} \mathrm{MgCl}$. The expected trace of calcium in the calcium free buffers is $1 \mathrm{nM}$ or less. The $\mathrm{pH}$ was measured after mixing of the buffers, and checked again before use.

Purified Tq-Ca-FLITS and jGCaMP7c were 100x diluted in the buffers and the intensity was recorded similar as done for the $\mathrm{pH}$ measurements. The dynamic range was calculated as the average intensity of the calcium bound state divided by the calcium free state. The lifetime of Tq-Ca-FLITS was recorded and processed in the same manner as described under $\mathbf{p H}$ sensitivity.

Endothelial Cell (EC) culture and transendothelial migration (TEM). Primary Human Umbilical Vein Endothelial Cells (HUVECs) acquired from Lonza (P1052, Cat \#C2519A) were maintained in culture flasks pre-coated with fibronectin (FN, $30 \mu \mathrm{g} / \mathrm{mL}$, Sanquin) in EGM-2 medium supplemented with SingleQuots (CC-3162, Lonza) and $\mathrm{P} / \mathrm{S}$, under $5 \%$ humidified $\mathrm{CO}_{2}$ atmosphere at $37{ }^{\circ} \mathrm{C}$. HUVECs were passaged by washing twice with phosphate buffered saline (PBS) and trypsinization. Trypsin was inactivated with Trypsin Neutralisation Solution (CC5002, Lonza). HUVECs were transfected by microporation at passage \#4 with $2 \mu \mathrm{g}$ plasmid DNA containing the Lck version of Tq-Ca-FLITS. For microporation the Neon Transfection System (MPK5000 Invitrogen) and corresponding Neon transfection kit were used according to manufacturers' protocol. We used the $\mathrm{R}$ buffer from the kit, the $100 \mu \mathrm{L}$ tips and a $30 \mathrm{~ms}$ pulse of $1300 \mathrm{~V}$. After microporation, HUVECs were directly seeded on FN-coated round cover slips for imaging, similar as described for HeLa cells. For TEM experiments, the buffer was removed by centrifugation ( $200 \mathrm{~g}, 3 \mathrm{~min}, \mathrm{RT})$ and HUVECs were seeded in a FNcoated $\mu$-Slide VI 0.4 (80606, Ibidi).

Polymorphonuclear cells, consisting mainly of neutrophils, were isolated from whole blood from healthy donors (Sanquin), stored 0/N at RT. Briefly, blood was diluted 1:1 in PBS with 5\% (v/v) trisodium citrate and pipetted on top of $12.5 \mathrm{~mL}$ Percoll $(1.047 \mathrm{~g} / \mathrm{mL}$ ) at RT. Cells were centrifuged at $800 \mathrm{~g}$ for $20 \mathrm{~min}$ (slow start, low brake) and all fractions except neutrophils and erythrocytes were removed. Erythrocytes were lysed twice in ice-cold isotonic lysis buffer $\left(155 \mathrm{mM} \mathrm{NH}_{4} \mathrm{Cl}\right.$, $10 \mathrm{mM} \mathrm{KHCO} 3,0.1 \mathrm{mM}$ EDTA). Remaining neutrophils were washed with PBS, followed by centrifugation at $450 \mathrm{~g}$ for $5 \mathrm{~min}$. Neutrophils were resuspended in HEPES medium (20 mM HEPES, $132 \mathrm{mM} \mathrm{NaCl}, 6 \mathrm{mM} \mathrm{KCl}, 1 \mathrm{mM} \mathrm{MgSO}_{4}, 1.2 \mathrm{mM}$ $\mathrm{K}_{2} \mathrm{HPO}_{4}, 1 \mathrm{mM} \mathrm{CaCl}$, 0.1\% D-glucose, 0.5\% Albuman (Sanquin Reagents)) and kept at RT for $4 \mathrm{~h}$ maximum. Neutrophils were prior to use labeled with $2 \mu \mathrm{M}$ Calcein Red-Orange dye for $20 \mathrm{~min}$ at $37^{\circ} \mathrm{C}$. Dye was removed by centrifugation and the neutrophils were directly used. Neutrophils were isolated from four donors.

Two days post-transfection, $\mu$-Slides containing HUVECs were stimulated with 10 $\mathrm{ng} / \mathrm{ml}$ TNF- $\alpha$. The slides were connected after $4 \mathrm{~h}$ to a closed perfusion system to mimic the blood flow. Cells were exposed to flow rates of 0.8 dynes $/ \mathrm{cm}^{2}$ (HEPES 
buffer) and kept under $5 \%$ humidified $\mathrm{CO}_{2}$ atmosphere at $37{ }^{\circ} \mathrm{C}$. Neutrophils where injected in the closed system to allow TEM. $100 \mu \mathrm{M}$ histamine or a mix of $10 \mu \mathrm{g} / \mathrm{ml}$ ionomycin and $5 \mathrm{mM}$ calcium was used as positive control for the sensor. Fluorescence lifetime was measured using the previously described LIFA setup, with a 40x (Plan Apo, NA 0.95 air) objective. Lifetime stacks in the cyan channel was recorded every $13.5 \mathrm{~s}$, alternated with an image in the red channel. For red excitation a $532 \mathrm{~nm}$ LED was used, combined with a $534 / 20 \mathrm{~nm}$ excitation filter, a $575 \mathrm{~nm}$ dichroic mirror and a 609/54 $\mathrm{nm}$ band-pass filter.

A background correction for removal of background lifetime was done on the lifetime stacks using a manually indicated background region. The background corrected data were used to calculate for each pixel the polar coordinates $M$ and $\Phi$ that represent the phase and modulation lifetimes ${ }^{63}$. The polar coordinates were corrected for daily variance compared to the in vivo calibration. To this end, the position of the recorded high lifetime state of the positive controls was forced to the position of the high lifetime state of the in vivo calibration. The corresponding correction factors (addition for ' $\Phi$ ' and division for ' $M$ ') were used to correct all recorded TEM data. Line fraction ' $a$ ' was calculated and converted into the calcium concentration using the in vivo calibration.

Neutrophils were manually tracked in ImageJ (version $1.52 \mathrm{k}$ ) to collect their intensities. The calcium concentration in the underlying HUVEC was extracted, as well as the cyan intensity. The stage of migration was manually assigned (crawling, diapedesis or post-diapedesis). Since diapedesis is a relatively rapid process, this yields a relatively low number of datapoints. We also measured the concentration before adhesion at the position where a neutrophil would adhere at a later timepoint and assigned the stage 'before'.

Organoid imaging. The study was approved by the UMC Utrecht (Utrecht, The Netherlands) ethical committee and was in accordance with the Declaration of Helsinki and according to Dutch law. This study is compliant with all relevant ethical regulations regarding research involving human participants.

Human intestinal organoids from the human ileum (N39; https://huborganoids.nl) stably expressing NLS-mMaroon and nuclear-targeted Tq-Ca-FLITS upon doxycycline induction were generated by lentiviral transduction and maintained as described elsewhere ${ }^{64}$. For differentiation towards EECs, organoids were treated with $1 \mu \mathrm{g} / \mathrm{mL}$ doxycycline for 48 hours, 5 days after seeding. 4 days later (day 6 of differentiation) organoids were analyzed. $10 \mu \mathrm{g} / \mathrm{ml}$ GPBAR-A (4478, Bio-Techne, Abingdon, United Kingdom) was added to the organoids while recording the fluorescence lifetime, using the previously described LIFA setup, with a 40x (Plan Apo, NA 0.95 air) objective. Lifetime stacks were recorded every $10 \mathrm{~s}$. For positive control we added $0.25 \%(\mathrm{w} / \mathrm{v})$ Triton-X100 together with $12.5 \mathrm{mM} \mathrm{CaCl}_{2}$.

Datasets were used to calculate for each pixel the polar coordinates $M$ and $\Phi$ that represent the phase and modulation lifetimes ${ }^{63}$. The polar coordinates were corrected for daily variance compared to the in vivo calibration. To this end, the position of the recorded high lifetime state of the positive controls was forced to the position of the high lifetime state of the in vivo calibration. The corresponding correction factors (addition for ' $\Phi$ ' and division for ' $M$ ') were used to correct the data. Line fraction ' $a$ ' was calculated and converted into the calcium concentration using the in vivo calibration. 
Reporting Summary. Further information on research design is available in the Nature Research Reporting Summary linked to this article.

\section{Data availability}

The data produced in this study are available within the article and its Supplementary Information.

All raw data will be available at Zenodo.org upon publication.

Plasmids are deposited for distribution through Addgene (www.addgene.org). The plasmids and corresponding addgene numbers are: pFHL-Tq-Ca-FLITS: \#129628, 3xnls-Tq-Ca-FLITS: \#129626, Lck-Tq-Ca-FLITS: \#129627, pPB-3xnlsTq-Ca-FLITS: \#145030, pLV-H2B-Maroon-P2A-3xnls-Tq-Ca-FLITS: \#145027, pInducer-mMaroon-NLS-P2A-3xnls-Tq-Ca-FLITS: being processed.

\section{Code availability}

Custom code and scripts are available through GitHub: https://github.com/Franka-van-der-Linden/Quantitative-Calcium-Imaging.

\section{Competing interests}

$\mathrm{HC}$ is an inventor on multiple patents related to organoid technology. For full disclosure see: https://www.uu.nl/staff/ICClevers/Additional functions.

\section{Author contributions}

F.H.L. and J.G. conceptualized the project, designed the experiments, interpreted the results and wrote the manuscript.

F.H.L., E.K.M., J.A. and J.v.B. participated in the experiments on endothelial cells and were involved in isolation of leukocytes.

J.P, J.D.B, B.P. and H.C. transduced and prepared organoids and assisted with experiments on organoids that were carried out by F.H.L.

A.O.C. generated stable HeLa cell lines.

S.M.A.M. performed FACS.

F.H.L., T.W.J.G. and M.P. were involved in FLIM experiments, performed data analysis and assisted with interpretation of the data.

All authors approved the final manuscript.

\section{Funding}

F.H.L. was supported by a NWO Chemical Sciences ECHO grant (711.017.003).

E.M. was supported by a NWO ALW-OPEN grant (ALWOP.306). M.P. was supported by a NWO-TTP grant (14691). J.v.B. was supported by a ZonMW NOW Vici grant (91819632).

The funders had no role in study design, data collection and analysis, decision to publish, or preparation of the manuscript. 


\section{References}

1. Sanford, L. \& Palmer, A. Recent Advances in Development of Genetically Encoded Fluorescent Sensors. Methods in Enzymology 589, (Elsevier Inc., 2017).

2. Inoue, M. et al. Rational Engineering of XCaMPs, a Multicolor GECI Suite for In Vivo Imaging of Complex Brain Circuit Dynamics. Cell 177, 1346-1360 (2019).

3. Dana, H. et al. High-performance calcium sensors for imaging activity in neuronal populations and microcompartments. Nat. Methods 16, 649-657 (2019).

4. Nagai, T., Sawano, A., Park, E. S. \& Miyawaki, A. Circularly permuted green fluorescent proteins engineered to sense Ca2+. Proc. Natl. Acad. Sci. 98, 3197-3202 (2001).

5. Nakai, J., Ohkura, M. \& Imoto, K. A high signal-to-noise Ca2+ probe composed of a single green fluorescent protein. Nat. Biotechnol. 19, 137141 (2001).

6. Zhao, Y. et al. An Expanded Palette of Genetically Encoded Ca2+ indicators. Science (80-. ). 333, 1888-1891 (2011).

7. Thomas, D. et al. A comparison of fluorescent Ca2+indicator properties and their use in measuring elementary and global Ca2+signals. Cell Calcium 28, 213-223 (2000).

8. Waters, J. C. Accuracy and precision in quantitative fluorescence microscopy. J. Cell Biol. 185, 1135-1148 (2009).

9. Barnett, L. M., Hughes, T. E. \& Drobizhev, M. Deciphering the molecular mechanism responsible for GCaMP6m's Ca2+-dependent change in fluorescence. PLoS One 12, 1-24 (2017).

10. Miyawaki, A. Fluorescence imaging of physiological activity in complex systems using GFP-based probes. Curr. Opin. Neurobiol. 13, 591-596 (2003).

11. Akerboom, J. et al. Crystal structures of the GCaMP calcium sensor reveal the mechanism of fluorescence signal change and aid rational design. J. Biol. Chem. 284, 6455-6464 (2009).

12. Ast, C. et al. Ratiometric Matryoshka biosensors from a nested cassette of green- and orange-emitting fluorescent proteins. Nat. Commun. 8, (2017).

13. Cho, J.-H. et al. The GCaMP-R Family of Genetically Encoded Ratiometric Calcium Indicators. ACS Chem. Biol. 12, 1066-1074 (2017).

14. Griesbeck, O., Baird, G. S., Campbell, R. E., Zacharias, D. A. \& Tsien, R. Y. Reducing the environmental sensitivity of yellow fluorescent protein. Mechanism and applications. J. Biol. Chem. 276, 29188-29194 (2001).

15. Chen, Y. \& Periasamy, A. Characterization of Two-photon Excitation Fluorescence Lifetime Imaging Microscopy for Protein Localization. Microsc. Res. Tech. 63, 72-80 (2004).

16. Herman, B. et al. Recent developments in monitoring calcium and protein interactions in cells using fluorescence lifetime microscopy. J. Fluoresc. 7, 85-91 (1997).

17. Van Munster, E. B. \& Gadella, T. W. J. Fluorescence Lifetime Imaging Microscopy (FLIM). Adv. Biochem. Eng. Biotechnol. 95, 143-175 (2005).

18. Zheng, K., Jensen, T. P. \& Rusakov, D. A. Monitoring intracellular nanomolar 
calcium using fluorescence lifetime imaging. Nat. Protoc. 13, 581-597 (2018).

19. Klarenbeek, J., Goedhart, J., Van Batenburg, A., Groenewald, D. \& Jalink, K. Fourth-generation Epac-based FRET sensors for cAMP feature exceptional brightness, photostability and dynamic range: Characterization of dedicated sensors for FLIM, for ratiometry and with high affinity. PLoS One 10, 1-11 (2015).

20. Colom, A. et al. A fluorescent membrane tension probe. Nat. Chem. (2018). doi:10.1038/s41557-018-0127-3

21. Lazzari-Dean, J. R., Gest, A. M. M. \& Miller, E. W. Optical estimation of absolute membrane potential using fluorescence lifetime imaging. Elife 8, 1-29 (2019).

22. Agronskaia, A. V., Tertoolen, L. \& Gerritsen, H. C. Fast fluorescence lifetime imaging of calcium in living cells. J. Biomed. Opt. 9, 1230-1237 (2004).

23. Akerboom, J. et al. Optimization of a GCaMP calcium indicator for neural activity imaging. J. Neurosci. 32, 13819-13840 (2012).

24. Borst, J. W. et al. Structural changes of yellow cameleon domains observed by quantitative FRET analysis and polarized fluorescence correlation spectroscopy. Biophys. J. 95, 5399-5411 (2008).

25. Díaz-García, C. M. et al. Neuronal Stimulation Triggers Neuronal Glycolysis and Not Lactate Uptake. Cell Metab. 26, 361-374 (2017).

26. Dana, H. et al. Sensitive red protein calcium indicators for imaging neural activity. Elife 5, 1-24 (2016).

27. Klarenbeek, J. B., Goedhart, J., Hink, M. A., Gadella, T. W. J. \& Jalink, K. A mTurquoise-based cAMP sensor for both FLIM and ratiometric read-out has improved dynamic range. PLoS One 6, 2-7 (2011).

28. Patterson, G., Day, R. N. \& Piston, D. Fluorescent protein spectra. J. Cell Sci. 114, 837-838 (2001).

29. Shen, Y. et al. A genetically encoded Ca2+indicator based on circularly permutated sea anemone red fluorescent protein eqFP578. BMC Biol. 16, 1-16 (2018).

30. Shemiakina, I. I. et al. A monomeric red fluorescent protein with low cytotoxicity. Nat. Commun. 3, (2012).

31. Mastop, M. et al. Characterization of a spectrally diverse set of fluorescent proteins as FRET acceptors for mTurquoise2. Sci. Rep. 7, 1-18 (2017).

32. Kredel, S. et al. mRuby, a bright monomeric red fluorescent protein for labeling of subcellular structures. PLoS One 4, (2009).

33. Goedhart, J. et al. Structure-guided evolution of cyan fluorescent proteins towards a quantum yield of 93\%. Nat. Commun. 3, (2012).

34. Cranfill, P. J. et al. Quantitative assessment of fluorescent proteins. Nat. Methods 13, 557-562 (2016).

35. Bindels, D. S., Postma, M., Haarbosch, L., van Weeren, L. \& Gadella, T. W. J. Multiparameter screening method for developing optimized redfluorescent proteins. Nat. Protoc. 15, 450-478 (2020).

36. Nelson, D. L. \& Cox, M. M. Lehninger Principles of Biochemistry, Fifth Edition. (W.H. Freeman and Company, 2008).

37. Halling, D. B., Liebeskind, B. J., Hall, A. W. \& Aldrich, R. W. Conserved properties of individual Ca2+-binding sites in calmodulin. Proc. Natl. Acad. Sci. U. S. A. 113, 1216-1225 (2016). 
38. Romani, A. \& Scarpa, A. Regulation of Cell Magnesium. Arch. Biochem. Biophys. 298, 1-12 (1992).

39. Yellen, G. \& Mongeon, R. Quantitative two-photon imaging of fluorescent biosensors. Curr. Opin. Chem. Biol. 27, 24-30 (2015).

40. Redford, G. I. \& Clegg, R. M. Polar plot representation for frequency-domain analysis of fluorescence lifetimes. J. Fluoresc. 15, 805-815 (2005).

41. Chen, T. W. et al. Ultrasensitive fluorescent proteins for imaging neuronal activity. Nature 499, 295-300 (2013).

42. Rotrosen, D. \& Gallin, J. I. Histamine type i receptor occupancy increases endothelial cytosolic calcium, reduces $\mathrm{f}$-actin, and promotes albumin diffusion across cultured endothelial monolayers. J. Cell Biol. 103, 23792387 (1986).

43. Heemskerk, N. et al. F-actin-rich contractile endothelial pores prevent vascular leakage during leukocyte diapedesis through local RhoA signalling. Nat. Commun. 7, (2016).

44. Dalal, P. J., Muller, W. A. \& Sullivan, D. P. Endothelial Cell Calcium Signaling during Barrier Function and Inflammation. Am. J. Pathol. 190, 535-542 (2020).

45. Worthen, L. M. \& Nollert, M. U. Intracellular calcium response of endothelial cells exposed to flow in the presence of thrombin or histamine. J. Vasc. Surg. 32, 593-601 (2000).

46. Tsai, F. C. \& Meyer, T. Ca2+ pulses control local cycles of lamellipodia retraction and adhesion along the front of migrating cells. Curr. Biol. 22, 837-842 (2012).

47. Beumer, J. et al. High-Resolution mRNA and Secretome Atlas of Human Enteroendocrine Cells. Cell 181, 1-16 (2020).

48. Alvarez, L. A. J. et al. SP8 FALCON: a novel concept in fluorescence lifetime imaging enabling video-rate confocal FLIM. Nat. Methods 20, (2019).

49. Raspe, M. et al. SiFLIM: Single-image frequency-domain FLIM provides fast and photon-efficient lifetime data. Nat. Methods 13, 501-504 (2016).

50. Kremers, G. J., Goedhart, J., Van Munster, E. B. \& Gadella, T. W. J. Cyan and yellow super fluorescent proteins with improved brightness, protein folding, and FRET förster radius. Biochemistry 45, 6570-6580 (2006).

51. Kretzschmar, K. \& Clevers, H. Organoids: Modeling Development and the Stem Cell Niche in a Dish. Dev. Cell 38, 590-600 (2016).

52. Gibson, D. G. et al. Enzymatic assembly of DNA molecules up to several hundred kilobases. Nat. Methods 6, 343-345 (2009).

53. Ponsioen, B. et al. Quantifying single-cell ERK dynamics in colorectal cancer organoids reveals EGFR as an amplifier of oncogenic MAPK pathway signalling. Nat. Cell Biol. 23, 377-390 (2021).

54. van Munster, E. B. \& Gadella, T. W. J. $\varphi$ FLIM: A new method to avoid aliasing in frequency-domain fluorescence lifetime imaging microscopy. J. Microsc. 213, 29-38 (2004).

55. Rusinova, E., Tretyachenko-Ladokhina, V., Vele, O. E., Senear, D. F. \& Alexander Ross, J. B. Alexa and Oregon Green dyes as fluorescence anisotropy probes for measuring protein-protein and protein-nucleic acid interactions. Anal. Biochem. 308, 18-25 (2002).

56. Ni, Y. \& Terpetschnig, E. Time-Domain Lifetime Measurements on ChronosBH. (2018). Available at: 
http://www.iss.com/resources/pdf/appnotes/Time_Domain_Lifetimes.pd f.

57. Boens, N. et al. Fluorescence Lifetime Standards for Time and Frequency Domain Fluorescence Spectroscopy. Anal. Chem. 79, 2137-2149 (2007).

58. Bastiaens, P. I. H., Wolkers, W. F., Visser, A. J. W. G., Van Hoek, A. \& Brochon, J. C. Comparison of the Dynamical Structures of Lipoamide Dehydrogenase and Glutathione Reductase by Time-Resolved Polarized Flavin Fluorescence. Biochemistry 31, 7050-7060 (1992).

59. van Munster, E. B. \& Gadella, T. W. J. Suppression of photobleachinginduced artifacts in frequency-domain FLIM by permutation of the recording order. Cytometry 58A, 185-194 (2004).

60. Merzlyak, E. M. et al. Bright monomeric red fluorescent protein with an extended fluorescence lifetime. Nat. Methods 4, 555-557 (2007).

61. Bindels, D. S. et al. Chapter 16: Optimization of Fluorescent Proteins. Fluorescence Spectroscopy and Microscopy 1076, (Methods in Molecular Biology, 2014).

62. Lelimousin, M. et al. Intrinsic dynamics in ECFP and cerulean control fluorescence quantum yield. Biochemistry 48, 10038-10046 (2009).

63. Gadella, T. W. J., Clegg, R. M. \& Jovint, T. M. Fluorescence lifetime imaging microscopy: pixel-by-pixel analysis of phase-modulation data. Bioimaging 2,139-159 (1994).

64. Koo, B. K. et al. Controlled gene expression in primary Lgr5 organoid cultures. Nat. Methods 9, 81-83 (2012).

65. Barrett, C. M. L., Ray, N., Thomas, J. D., Robinson, C. \& Bolhuis, A. Quantitative export of a reporter protein, GFP, by the twin-arginine translocation pathway in Escherichia coli. Biochem. Biophys. Res. Commun. 304, 279-284 (2003).

66. Huang, A. J. et al. Endothelial cell cytosolic free calcium regulates neutrophil migration across monolayers of endothelial cells. J. Cell Biol. 120, 1371-1380 (1993).

67. Ziegelstein, R. C. et al. Initial contact and subsequent adhesion of human neutrophils or monocytes to human aortic endothelial cells releases an endothelial intracellular calcium store. Circulation 90, 1899-1907 (1994).

68. Pfau, S. et al. Lymphocyte adhesion-dependent calcium signaling in human endothelial cells. J. Cell Biol. 128, 969-978 (1995).

69. Ehringer, W. D., Edwards, M. J., Wintergerst, K. A., Cox, A. \& Miller, F. N. An Increase in Endothelial Intracellular Calcium and F-Actin Precedes the Extravasation of Interleukin-2-Activated Lymphocytes. Microcirculation 5, 71-80 (1998).

70. Kielbassa-Schnepp, K. et al. Endothelial intracellular Ca2+ release following monocyte adhesion is required for the transendothelial migration of monocytes. Cell Calcium 30, 29-40 (2001).

71. Peterson, M. D. et al. Monocyte-induced endothelial calcium signaling mediates early xenogeneic endothelial activation. Am. J. Transplant. 5, 237-247 (2005).

72. Heemskerk, N., Asimuddin, M., Oort, C., van Rijssel, J. \& van Buul, J. D. Annexin A2 Limits Neutrophil Transendothelial Migration by Organizing the Spatial Distribution of ICAM-1. J. Immunol. 196, 2767-2778 (2016). 


\section{Supplemental Notes}

\section{Supplementary note 1. Construction of the dual expression plasmid pFHL.} To allow fast and easy screening of sensor candidates, a dedicated expression vector was designed, termed pFHL, inspired by the plasmids pDuEx (pDress ${ }^{35}$ were the mTurquoise2, large spatial linker and P2A sequences were removed from the plasmid using NheI restriction sites) and pTorPE $^{6}$. The protein of interest, in this case a candidate sensor, is under control of a CMV promotor for mammalian expression and a rhamnose promotor for bacterial expression. This will eliminate the need of transferring the candidate sensor to a vector for mammalian expression after bacterial screening. At the $\mathrm{N}$-terminus, the sensor is fused to a TorA tag, a 6xHis-tag and an Xpress-tag. The TorA tag primes transport of the sensor to the periplasm of bacteria ${ }^{65}$. As a result, changing the outer environment, for example adding a compound to an agar plate or to a liquid culture, will directly influence the candidate sensor. Also, easy periplasmic isolation will yield a relatively clean protein, ready for quick testing ${ }^{6}$. The $6 x$ Histag and the Xpress-tag can be used for protein isolation.

The optimal concentration of rhamnose for expression in E. coli using the pFHL vector was determined to be $0.4 \%(\mathrm{w} / \mathrm{v}$ ) (Figure S4A). The performance of the dual expression vector was verified in E. coli and HeLa cells, and compared to the pTorPE plasmid. When expressed in E. coli, the R-GECO1 sensor reacted to changing calcium concentration in liquid growth medium (Figure S4B). A bigger response was obtained when the sensor was first isolated by isolation of the periplasmid fluid with an osmotic shock. The contrast was lower using the pFHL vector compared to the TorPE vector. However, we found that the contrast was sufficient for screening. The vector also allowed expression in HeLa cells, where addition of ionomycin and extra calcium resulted in a robust intracellular calcium increase, necessary for lifetime measurements (Figure 1B).

\section{Supplementary note 2 . Influence of residue 150 in mTurquoise 2 on fluorescence lifetime.}

Amino acid V150 is positioned close to the chromophore in mTurquoise 2 and therefore we suspected it to affect the fluorescent lifetime of the protein. We randomly mutated this position. Fluorescent and dark colonies were picked and collected on two plates, from which the modulation lifetime was measured using frequency domain FLIM (Figure S6) using a custom build FLIM setup and analysis as described before ${ }^{61}$. Lifetimes between 2.4-4.0 ns were recorded among the fluorescent colonies.

\section{Supplementary note 3 . Changing the calcium concentration in the periplasm of bacteria on agar plates.}

E. coli cells expressing Tq-Ca-FLITS.0 were grown on LB-agar plates. The modulation lifetime $\left(\tau_{M}\right)$ of the sensor was measured before and $>5$ min after 1,2 or 3 stimulations with a droplet of calcium or chelator EDTA (Figure S7). The lifetime was recorded of the whole plate using a custom build FLIM setup and analysis as described before ${ }^{61}$. 
Addition of calcium increased the $\tau_{M}$ from $2.70 \pm 0.03$ ns to $2.83 \pm 0.02$ ns (mean \pm sd). Adding more calcium to a colony did not further increase the lifetime. Addition of $200 \mathrm{mM}$ EDTA decreased the lifetime to $2.51 \pm 0.07 \mathrm{~ns}, 2.33 \pm 0.08 \mathrm{~ns}$ and $2.15 \pm 0.11 \mathrm{~ns}$ for 1,2 and 3 drops respectively. The results show that the sensors in bacteria on LB-agar are primarily in the high lifetime state and that the sensors can indeed be influenced from the outer environment, as a result of expression in the periplasmic space. 
bioRxiv preprint doi: https://doi.org/10.1101/2021.06.21.449214 this version posted June 21 2021. The copyright holder for this preprint (which was not certified by peer review) is the author/funder, who has granted bioRxiv a license to display the preprint in perpetuity. It is made available under aCC-BY-NC-ND 4.0 International license.

\section{Supplementary note 4 . Calcium concentrations during transendothelial migration}

Several reports have documented the use of calcium sensitive probes to study changes in calcium levels in endothelial cells upon their interaction with white blood cells. These studies are summarized in Table S6.

Table S6. Summary of studies that investigate calcium during TEM.

\begin{tabular}{|c|c|c|c|c|c|c|c|}
\hline $\begin{array}{l}\text { Calcium } \\
\text { increase }\end{array}$ & $\begin{array}{l}\text { Endothe- } \\
\text { lial cells }\end{array}$ & $\begin{array}{l}\text { White } \\
\text { blood cell }\end{array}$ & $\begin{array}{l}\text { Probe } \\
\text { (loading } \\
\text { conditions) }\end{array}$ & $\begin{array}{l}\text { Single } \\
\text { cell }\end{array}$ & Flow & Stage & Ref. \\
\hline$>800 \mathrm{nM}$ & HUVEC & $\begin{array}{l}\text { PMN (10:1) } \\
+ \text { fMLP }\end{array}$ & $\begin{array}{l}\text { Fura-2 } \\
\left(18^{\circ} \mathrm{C} \&\right. \\
\text { Pluronic) }\end{array}$ & yes & no & Adhesion & {$\left[{ }^{66}\right]$} \\
\hline $\begin{array}{l}\text { Yes, } \\
\text { qualitative }\end{array}$ & HAEC & $\begin{array}{l}\text { PMN } \\
(5-10: 1)\end{array}$ & $\begin{array}{l}\text { Indo-1 } \\
\left(23^{\circ} \mathrm{C}, \mathrm{RT}\right)\end{array}$ & no & no & Adhesion & {$[67]$} \\
\hline $\begin{array}{l}\text { Yes, } \\
\text { qualitative }\end{array}$ & HUVEC & $\begin{array}{l}\mathrm{CD} 65+/ \mathrm{NK} \\
\text { (20:1 ratio) }\end{array}$ & $\begin{array}{l}\text { Fluo-3 } \\
\left(22^{\circ} \mathrm{C} \&\right. \\
\text { Pluronic })\end{array}$ & yes & no & Adhesion & [68] \\
\hline $180 \mathrm{nM}$ & $\begin{array}{l}\text { Lung } \\
\text { HMVEC }\end{array}$ & $\begin{array}{l}\text { Lymphocyte } \\
\left(10^{5} / \mathrm{ml}\right)\end{array}$ & $\begin{array}{l}\text { Fura-2 } \\
\left(37^{\circ} \mathrm{C} \&\right. \\
\text { Pluronic) }\end{array}$ & no & no & Adhesion & [69] \\
\hline $\begin{array}{l}\text { Qualitative: } \\
\sim 60 \% \text { of cells }\end{array}$ & HMEC-1 & $\begin{array}{l}\text { Monocytes } \\
(10: 1)\end{array}$ & $\begin{array}{l}\text { Indo-1 } \\
\text { (RT) }\end{array}$ & yes & no & Adhesion & {$\left[{ }^{70}\right]$} \\
\hline$\sim 200 \mathrm{nM}$ & HAEC & Monocytes & $\begin{array}{l}\text { Fura-2 } \\
\left(24^{\circ} \mathrm{C}\right)\end{array}$ & yes & no & Adhesion & {$\left[{ }^{71}\right]$} \\
\hline $\begin{array}{l}\text { Qualitative: } \\
\sim 25 \% \text { of cells }\end{array}$ & HUVEC & Neutrophils & YCaM & yes & yes & Rolling & [72] \\
\hline $\begin{array}{l}\text { Qualitative: } \\
\text { None of the } \\
\text { cells }\end{array}$ & HUVEC & Neutrophils & YCaM & yes & yes & Crawling & {$\left[{ }^{72}\right]$} \\
\hline No: $<80 \mathrm{nM}$ & HUVEC & Neutrophils & Tq-Ca-FLITS & yes & yes & $\begin{array}{l}\text { Crawling \& } \\
\text { diapedesis }\end{array}$ & $\begin{array}{l}\text { This } \\
\text { study }\end{array}$ \\
\hline
\end{tabular}

The increase in calcium concentration that is observed in endothelial cells varies. This can be partially attributed to the different experimental conditions that are used. Here, we have tried to approach the physiological situation as close as possible by (i) studying TEM under flow at $37^{\circ} \mathrm{C}$, (ii) pretreating the endothelial monolayer with TNF to mimic inflamed conditions, (iii) activating the freshly isolated leukocytes by $20 \mathrm{~min}$ incubation at $37^{\circ} \mathrm{C}$ and (iv) omitting any of the perturbations that are necessary for labeling cells with fluorescent dyes. Specifically, the use of a genetically encoded probe does not require preincubation at room temperature, does not need helper reagents (Pluronic) and omits issues with dye leakage and incomplete hydrolysis. Moreover, Tq-Ca-FLITS uses visible light for excitation (in contrast to Indo-1 and Fura-2 which require UV) and enables direct, intensity-independent quantification.

Finally, we have fluorescently labeled both cell types and can therefore precisely analyze the interaction between two cell types and distinguish the different phases of TEM. 


\section{Supplemental Movies}

Supplementary movie S1: Calcium calibration in HeLa cells that express a nuclear tagged Tq-Ca-FLITS biosensor. The intensity and phase lifetime data are shown after cell permeabilization and equilibration at different external calcium concentrations.

Supplementary movie S2: Calcium levels in endothelial cells monitored with plasma membrane targeted Tq-Ca-FLITS before and after stimulation with $1 \mu \mathrm{M}$ histamine. Displayed are on the left the intensity of the probe is shown and on the right the calcium concentration calculated from the lifetime data in false color according to the color scale.

Supplementary movie S3: Calcium levels in endothelial cells monitored with plasma membrane targeted Tq-Ca-FLITS during transendothelial migration. Displayed are on the left the intensities of the probe and the neutrophil (in cyan and red respectively) and on the right the calcium concentration calculated from the lifetime data in false color according to the color scale. The white region of interest shows the location of the neutrophil, showing that calcium is not elevated in this region.

Supplementary movie S4: Calcium changes measured in nuclei of human small intestinal organoids stimulated with $10 \mu \mathrm{g} / \mathrm{ml}$ GPBAR-A at $25 \mathrm{sec}$. Displayed are on the left the intensity of the probe and on the right the calcium concentration calculated from the lifetime data in false color according to the color scale. 